\title{
Migration and Trade: Theory with an Application to the Eastern-Western European Integration
}

\author{
Susana Iranzo (Universitat Rovira Virgili) \\ Giovanni Peri (University of California Davis, CESifo and NBER)*
}

This Draft: March 2009

\begin{abstract}
The remarkable increase in trade flows and in migratory flows of highly educated people are two important features of globalization of the last decades. This paper extends a two-country model of inter- and intraindustry trade to a rich environment featuring technological differences, skill differences and the possibility of international labor mobility. The model is used to explain the patterns of trade and migration as countries remove barriers to trade and to labor mobility. We parameterize the model to match the features of the Western and Eastern European members of the EU and analyze first the effects of the trade liberalization which occured between 1989 and 2004, and then the gains and losses from migration which are expected to occur if legal barriers to labor mobility are substantially reduced. The lower barriers to migration would result in significant migration of skilled workers from Eastern European countries. Interestingly, this would not only benefit the migrants and most Western European workers but, via trade, it would also benefit the workers remaining in Eastern Europe.
\end{abstract}

Key Words: Skilled Migration, Gains from Variety, Real Wages, Eastern-Western Europe.

JEL Codes: F12, F22, J61.

\footnotetext{
*Susana Iranzo, Universitat Rovira Virgili, Avda. Universitat 1, Reus 43204, Spain, susana.iranzo@urv.cat. Giovanni Peri, University of California, Davis, One Shields Avenue, Davis CA 95616, gperi@ucdavis.edu. We thank Jim Rauch and two anonymous referees for helpful comments and suggestions. Jaime Alonso, Giovanni Facchini, Robert Feenstra, James Harrigan, Anna Maria Mayda, Andres Rodriguez-Clare, Jakob von Weizsäcker and participants in several seminars and conferences also provided helpful suggestions. Peri acknowledges the John D. and Catherine T. MacArthur Foundation for generously funding his research on international migrations.
} 


\section{Introduction}

Trade flows have increased substantially in the last decades. As of 2000, the average country in the world was selling and buying abroad a value equal to $27 \%$ of its gross domestic product. In contrast, labor flows increased much less. In 2000 only $1.8 \%$ of the world population was living in an OECD country different from their country of birth (Freeman 2006). Recent data (Docquier and Marfouk, 2005) and studies (Grogger and Hanson 2008) have shown that a partial exception to this low labor mobility is the behavior of highly educated workers. Up to $15 \%$ of the individuals with tertiary education from some less developed countries reside abroad (usually in an industrialized country) and this segment has become increasingly more mobile than the rest of the population. Table 1 reports the emigration rates by educational group for some representative source countries, ${ }^{1}$ calculated as the stock of people residing abroad divided by the working-age population in that group in the country of origin. ${ }^{2}$ We notice that in 2000 the emigration rates for the highly educated were much larger than for any other group. Furthermore, they generally grew during the 1990s by more than those of the other groups. For instance, for Romania, a typical Eastern European economy, and for Eastern Europe as a whole (last two rows of Table 1) the emigration rates of the highly educated were two to three times larger than the emigration rates of the less educated. As barriers to labor mobility within the European Union are dismantled, ${ }^{3}$ the flow of highly educated workers from the East is expected to increase.

The migration of highly educated workers, often called "brain drain", has attracted the attention of policymakers and economists. Generally, the cost of losing the best educated workers is considered to be high for the sending countries. At the same time, though, several economists have recognized that from a world perspective international restrictions on labor mobility are one of the most costly economic distortions. ${ }^{4}$ This paper exploits the fact that Western and Eastern Europe are potential testing grounds for the impact of free labor mobility between regions that have achieved trade integration but still have significant differences in productivity. We develop a model capable of predicting the patterns and effects of free labor mobility between economies that trade with each other but have significant productivity (technological) differences and where workers are heterogeneous in their education (skill) levels. Such a model is novel relative to those combining Heckscher-Ohlin and monopolistic competition (such as Krugman, 1981) because it also incorporates technological differences and heterogeneous agents, which are critical to determine the direction and selection of migrants. On the other hand it is novel relative to those models that combine Heckscher-Ohlin features and heterogeneous agents (such

\footnotetext{
${ }^{1}$ The data are from Docquier and Marfouk (2005) who collected information from Censuses of resident populations in OECD countries in the year 2000.

${ }^{2}$ The table distinguishes between less educated ( 0 to 8 years of schooling), those with intermediate education ( 9 to 12 years of schooling) and the highly educated (13 years of schooling or more)

${ }^{3}$ The accession treaty that admitted ten new countries to the EU in 2004, and Romania and Bulgaria in 2006, contained transitional arrangements that allowed the old EU members to postpone the opening of their labour markets for at least two years and, at most, seven years. A detailed description of the labor market restrictions in place and the provision of transitional agreements can be found in Boeri and Brucker (2005).

${ }^{4}$ See, for example, Klein and Ventura (2007), Kremer and Watt (2006) or Benhabib and Jovanovic (2007).
} 
as Rauch 1991) because it includes monopolistic competition and technological differences, which are critical to obtain gains from international migration.

More precisely, we propose a two-country ("West" and "East"), two-sector ("Homogeneous" and "Differentiated") model with workers of different skill levels and skill-specific technological differences across countries. In particular, the West has higher total factor productivity (TFP), a larger market size and a more skillcomplementary technology conferring to it a comparative advantage in the high-tech sector. The model features the traditional "comparative advantage" motive for inter-industry trade. However, due to technological differences across countries trade does not imply factor price equalization. Thus, even under free trade, lifting the restrictions on the free movement of workers would induce migratory flows. At the same time, the model incorporates love for variety and a home market effect in the differentiated sector, which imply that trade has a welfare enhancing effect on both countries.

An important feature of the model is that it incorporates agents of different skill (schooling) levels and generates plausible migration patterns. The complementarity between technology and high skills in the differentiated sector, more pronounced in the West, implies that highly educated workers have the greatest incentive to migrate from the East to the West. These incentives are somewhat reduced but not eliminated by trade. An important and novel result of the paper is that, in the presence of trade, the migration of the highly skilled workers may be beneficial to both the sending and the receiving country. This is because the Eastern European migrants are more productive in the West and thus increase the total production of the differentiated consumption goods at lower prices that Eastern consumers also enjoy via trade. Such trade-mediated "spillovers" of skilled migrants have not been pointed out in the literature before. ${ }^{5}$ As we show, the gains can be quantitatively relevant, especially when trade is large, trade costs are small and productivity differences are significant.

More generally our model, calibrated to Eastern and Western European economies, generates the following three main predictions:

- First, labor allocation of workers is currently distorted by the presence of large legal barriers to labor mobility. The estimated current migration costs due to legal barriers are equivalent to $26 \%$ of the wage income that the migrants would receive in Western Europe. If those costs were reduced to half of their current value, about $9 \%$ of the Eastern European population of working age, selected among those with secondary and some tertiary education, would work in the West. Currently only $1.48 \%$ of Eastern-born workers reside in Western Europe.

- Second, highly educated migrants (with more than a secondary education) would be the group gaining the most from reduced barriers to mobility. They would earn real wages between $60 \%$ and $100 \%$ higher

\footnotetext{
${ }^{5}$ Recently Broda and Weinstein (2006) have measured the sizeable gains from imported varieties in the US (equal to $2.4 \%$ of the GDP as of 2001).
} 
than they currently do.

- Third, given the flow of goods and services between the East and the West measured as of 2004, if legal costs were reduced to half of their current value the gains from increased variety that migrants would generate would offset the negative "brain drain" effect on East European, and workers left behind in the East would experience a small real average wage increase of around $0.1 \%$.

The rest of the paper is organized as follows. section 2 reviews the existing literature. Section 3 describes the model and the equilibrium in autarky while section 4 compares the autarky equilibrium with the equilibria in the presence of trade and then with trade and migration. The calibration of the model to the data for Eastern and Western Europe is detailed in section 5, where the model is also simulated to evaluate the (comparative static) welfare gains from trade and migration. Section 6 summarizes the main results and concludes.

\section{Literature Review}

Many of the models that analyze the determinants and the effects of international migration use a simplified framework often based on the Heckscher-Ohlin model or the specific factors model. ${ }^{6}$ In a world where land is an important factor of production these models still provide some useful insights. ${ }^{7}$ They can also be helpful if we simply want to explain overall migration tendencies to capital-abundant (rich) countries from capital-scarce (poor) countries. However, neither model is particularly well suited to analyze migration and trade together, mainly because in these models trade and migration are substitutes for one another. ${ }^{8}$ Moreover, once we consider highly educated and less educated workers as different factors of production, the factor endowment model wrongly predicts the direction of skilled migration: educated migrants should move from rich (skill abundant) to poor (skill scarce) countries. Alternatively, international movements of factors (capital and labor) have also been analyzed in models where countries have different total factor productivity (TFP) and those differences are the only determinants of factor flows (Lucas 1990, Davis and Weinstein 2002). Yet, surprisingly, what is missing in the recent international migration literature is any consideration of the features that have held center-stage in the new trade theories: monopolistic competition (and the gains from trade due to increased variety) and heterogeneity in the productivity of agents. Our model introduces these two elements into a model of trade and migration that, consistent with previous models, also features comparative advantage and TFP differentials between countries.

\footnotetext{
${ }^{6}$ See for instance Chapter 7 of Krugman and Obtsfeld (2006), still the most popular undergraduate textbook on International Economics, and Chapter 5 of Feenstra (2008). See also Mundell (1957) and Wong (1986).

${ }^{7}$ Hatton and Williams (2005) and (2006) use factor-endowment models with land and labor to analyze the migration from Europe to the US in the early 20 th century.

${ }^{8} \mathrm{Or}$ also, because there is only one good being produced and thus there is no trade at all.
} 
Related to our work is Rauch (1991) which reconciles the patterns of migration and trade within a HeckscherOhlin model where skilled workers can work as managers or workers and differ in their managerial abilities. ${ }^{9}$ In such a framework the skill abundant country has a larger group of managers who increase the productivity of workers and their wages. Moreover, the ability of the marginal worker who is indifferent between being a manager or a worker is higher in the skill-abundant country than in the skill-scarce country. Therefore, workers who have skills in between the thresholds of the two countries have incentives to migrate from the skill-scarce to the skill-abundant country. Relative to Rauch (1991), our model allows for a richer set-up with intra-industry trade (driven by economies of scale and love for variety) and productivity differences across countries. Our model uncovers a new channel of gains from migration. Due to the increased productivity of migrants in the receiving country and their contribution to the production of differentiated goods, the sending country may also gain from migration by accessing a larger number of varieties at lower prices. ${ }^{10}$

Our paper also contributes to the sizeable literature on the "brain drain". This literature has traditionally emphasized the costs of losing a country's best educated workers. ${ }^{11}$ On the other hand, some studies have pointed out possible benefits derived from the brain drain, such as the productivity opportunities that international mobility generates for the skilled migrants (Bhagwati and Rodriguez 1975; Bhagwati and Hamada 1974), the creation of international networks (diaspora) to channel transfers of knowledge and stimulate trade (Rauch and Trinidade 2002), the possibility of return of skilled workers (Kapur and McHale 2005) and the incentives that migration might create for human capital formation in the sending countries (Mountford 1997, Stark 2004, Beine et al 2001). Our model adds to those benefits the possibility of trade-mediated gains from increased varieties. Finally, of related interest to our work is Klein and Ventura (2006), the only other paper we know of that quantifies the effects on wages and migration flows of East-West European economic integration. They use a model with TFP differences and migration costs to analyze the effects of removing migration restrictions in Europe. ${ }^{12}$ In addition to those elements, our model considers trade, skill-specific technology and worker heterogeneity, all absent in Klein and Ventura (2006). Moreover, we analyze trade liberalization between Eastern and Western Europe as an intermediate step between economic autarky and free mobility of workers.

\footnotetext{
${ }^{9}$ An early attempt to explain the brain drain to rich countries invoking increasing returns to human capital was Miyagiwa (1991).

${ }^{10}$ The only study that analyzes, from a theoretical point of view, a mechanism somewhat reminiscent of ours is Kuhn and McAusland (2006). They develop a model of gains from brain drain based on externalities stemming from the knowledge creation activity that spills over to the sending country. That paper, however, emphasizes market size differences rather than productivity differences, and knowledge diffusion, rather than trade, as the channel for the positive spillover effects.

${ }^{11}$ For instance, the "fiscal loss" from the flight of high income earners (Bhagwati and Hamada 1974), the negative growth effect from the loss in human capital (Wong and Yip 1999) and the loss of potential positive human capital externalities in productivity (Benhabib and Jovanovic 2007).

${ }^{12}$ Klein and Ventura (2006) develop a fully dynamic model that can analyze the transition process while our static analysis should be thought of as comparing steady state equilibria.
} 


\section{The Model}

We develop a two-country, two-sector model building on Iranzo and Peri (2009) which in turn builds on Yeaple (2005). We begin by presenting the main setup of the model and the equilibrium in the absence of trade and migration. In this section we also study analytically how specialization, prices and wages are affected by the market size, the productivity and the educational distribution of the country in autarky. This provides useful insights in order to understand the effects of trade and migration once we allow (in section 4) for the international movement of goods and workers.

\subsection{Preferences and Demand}

Let us consider two economies labelled 1 (West) and 2 (East) whose residents have identical preferences. Two goods are being consumed in each economy: a homogeneous good $Y$ and a differentiated good $X .{ }^{13}$ The preferences of the representative consumer in country $j$ are described by a Constant Elasticity of Substitution (CES) utility function over goods $X$ and $Y$ and the two goods are assumed to be gross substitutes:

$$
U_{j}=\left[(1-\beta) Y_{j}^{\frac{\theta-1}{\theta}}+\beta X_{j}^{\frac{\theta-1}{\theta}}\right]^{\frac{\theta}{\theta-1}} \quad \text { with } \quad \theta>1
$$

The composite good $X$ is in turn represented by a CES aggregator over a continuum of varieties, indexed by $i$ :

$$
X_{j}=\left(\int_{0}^{N_{j}} x(i)^{\frac{\sigma-1}{\sigma}} d i\right)^{\frac{\sigma}{\sigma-1}} \quad \text { with } \quad \sigma>\theta>1, \quad j=1,2
$$

where $x(i)$ represents the amount of variety $i$ consumed and $N_{j}$ is the number of varieties of good $X$ produced in country $j$. The parameter $\sigma$ captures the elasticity of substitution across varieties and is assumed to be larger than the elasticity of substitution between goods $X$ and $Y(\theta)$ so that the different varieties of $X$ are closer substitutes for each other than for good $Y$. Taking good $Y$ as the numeraire in each country and defining $E_{j}$ as the aggregate expenditure in country $j$, one can derive the total goods demand in country $j, X_{j}^{D}$ and $Y_{j}^{D}$, and the demand for each variety of good $X, x_{j}^{D}(i)$, as follows:

$$
\begin{aligned}
& X_{j}^{D}=\beta^{\theta} \frac{E_{j}}{P_{j}}\left(\frac{P_{X j}}{P_{j}}\right)^{-\theta} \quad Y_{j}^{D}=(1-\beta)^{\theta} \frac{E_{j}}{P j}\left(\frac{1}{P_{j}}\right)^{-\theta} \quad j=1,2 \\
& x_{j}^{D}(i)=\left(\frac{s\left(P_{X j}\right) E_{j}}{P_{X j}}\right)\left(\frac{p_{j}(i)}{P_{X j}}\right)^{-\sigma}
\end{aligned}
$$

\footnotetext{
${ }^{13}$ Most of the propositions proved below carry through, with more cumbersome algebra and notation, if we also consider $Y$ as a differentiated good produced in monopolistic competition. In that case we need the elasticity of substitution across varieties of $Y$, $\sigma_{Y}$, to be larger than the elasticity of substitution across varieties of $X, \sigma_{X}$, and both to be larger than $\theta$.
} 
where $P_{j}=\left[\beta^{\theta} P_{X j}^{1-\theta}+(1-\beta)^{\theta}\right]^{\frac{1}{1-\theta}}$ is the overall price index in country $j$ and it is monotonically increasing in $P_{X j}=\left[\int_{0}^{N_{j}} p_{j}(i)^{1-\sigma} d i\right]^{\frac{1}{1-\sigma}}$, the price of the composite good $X$. The term $p_{j}(i)$ denotes the price of variety $i$ produced in country $j$. Finally, $s\left(P_{X j}\right)=\left(\beta^{\theta} P_{X j}^{1-\theta}\right) /\left[\beta^{\theta} P_{X j}^{1-\theta}+(1-\beta)^{\theta}\right]$ is the share of expenditure devoted to good $X$ in country $j$.

\subsection{Production}

There is only one factor of production: labor. Workers differ in their skill level which we denote $Z \in[0,1]$. The distribution of workers' skills in country $j$ is given by the cumulative density function $G_{j}(Z)$ and in each country $j$ there is a total mass of workers equal to $M_{j}$. We call $W_{j}(Z)$ the wage (in terms of the numeraire) that a worker of skill $Z$ receives in country $j$. As labor is the only factor of production, the aggregate labor income in country $j$ equals its GDP and, given the static nature of the model, it is also equal to the aggregate expenditure $E_{j}$ :

$$
E_{j}=M_{j} \int_{0}^{1} W_{j}(Z) d G_{j}(z)
$$

We assume that good $Y$ is produced using a constant returns to scale technology. The function $A_{Y j}(Z)$ expresses the amount of good $Y$ produced by a worker of skill $Z$ in country $j$, that is, the productivity of skill $Z$ in units of the numeraire. Similarly, $A_{X j}(Z)$ indicates the amount of good $X$ produced by a worker of skill $Z$ in country $j$. The technology of sector $X$ is relatively more productive for highly skilled workers than the technology of sector $Y$. Also, each country $j$ may have a specific productivity level (TFP) and a specific degree of skill bias in each sector (maintaining the assumption that in either country sector $X$ is more skill-intensive than sector $Y$ ). These assumptions are summarized by the following functional forms and parameter restrictions:

$$
A_{Y j}(Z)=\Lambda_{j} \exp \left(g_{Y j} Z\right), \quad A_{X j}(Z)=\Lambda_{j} \exp \left(g_{X j} Z\right) \quad \text { with } g_{X j}>g_{Y j}, \quad j=1,2
$$

where $\Lambda_{j}$ captures the TFP of country $j$ and $g_{Y j}$ and $g_{X j}$ the degree of complementarity between technology and skills. Another difference between the traditional and the modern sector is that each variety of good $X$ requires a fixed cost in the form of output that cannot be sold -we should think of this as a product development fixed cost. ${ }^{14}$ This fixed cost is denoted by $F_{X j}$. Finally, there is free entry in sector $X$ and each firm in this sector produces one and only one variety of good $X$.

\footnotetext{
${ }^{14} \mathrm{By}$ contrast, no fixed costs are required in sector $Y$.
} 


\subsection{Wage Schedule}

Labor markets are assumed to be perfectly competitive so that each worker is paid the value of her marginal product and the wage distribution over skills, $Z$, adjusts in order to equalize the unit cost of all firms using the same technology. Given the technologies described above, the costs of producing one unit of good $Y$ and one unit of (any variety of) good $X$ in country $j$ are, respectively:

$$
\begin{aligned}
& C_{Y j}=W_{Y j}(Z) /\left[\Lambda_{j} \exp \left(g_{Y j} Z\right)\right] \quad j=1,2 \\
& C_{X j}=W_{X j}(Z) /\left[\Lambda_{j} \exp \left(g_{X j} Z\right)\right] \quad j=1,2
\end{aligned}
$$

Perfect competition in sector $Y$ ensures that prices are equal to unit costs which, given the choice of good $Y$ as the numeraire, implies $1=P_{Y 1}=P_{Y 2}=C_{Y}$. Workers choose to work in the sector where they receive the highest wages. As proved in Yeaple (2005), there exists a worker indifferent between working in one sector or the other and whose skill level, denoted as $\bar{Z}_{j}$, is found via the following inter-industry wage equalization condition:

$$
W_{Y j}\left(\bar{Z}_{j}\right)=W_{X j}\left(\bar{Z}_{j}\right) \quad j=1,2
$$

Workers below the cut-off skill level $\bar{Z}_{j}$ receive higher wages in sector $Y$ and thus choose to work there, while workers with skills above $\bar{Z}_{j}$ are better off working in sector $X$. Consequently, the equilibrium wage schedule in country $j$ is given by:

$$
W_{j}(Z)=\left\{\begin{array}{c}
\Lambda_{j} \exp \left(g_{Y j} Z\right) \quad 0 \leq Z \leq \bar{Z}_{j} \\
\Lambda_{j} C_{X j} \exp \left(g_{X j} Z\right) \quad \bar{Z}_{j} \leq Z \leq 1
\end{array} \quad j=1,2\right.
$$

where $C_{X j}=\exp \left(g_{Y j} \bar{Z}_{j}\right) / \exp \left(g_{X j} \bar{Z}_{j}\right)$. The value of the threshold $\bar{Z}_{j}$ is endogenously determined in equilibrium, and with it one can characterize the entire wage schedule. The logarithmic wage schedule (measured in units of the numeraire) is a piece-wise linear function with a kink at $\bar{Z}_{j}$. Given the parameter restrictions, it has a steeper gradient to the right of the kink. Panels A and B of Figure 1 show its typical shape and the effects, discussed below, of changing several parameters.

Aggregating over workers with different skills and dividing by the mass of workers we obtain the average wage in country $j$, which is equal to its per capita income in terms of the numeraire, and is given by:

$$
\bar{W}_{j}=\Lambda_{j}\left(\int_{0}^{\bar{Z}_{j}} \exp \left(g_{Y j} Z\right) d G_{j}(Z)+C_{X_{j}} \int_{\bar{Z}_{j}}^{1} \exp \left(g_{X j} Z\right) d G_{j}(Z)\right)
$$




\subsection{Equilibrium}

We solve separately for the equilibrium of each country $j=1,2$ in autarky. Profit maximization and free entry yield the optimal price and quantity for each variety $i$ of good $X$, as follows:

$$
p_{j}(i)=\frac{\sigma}{\sigma-1} C_{X j} \quad x_{j}(i)=(\sigma-1) F_{X j} \quad \text { for } i \in\left[0, N_{j}\right]
$$

In the symmetric equilibrium the varieties of the differentiated good $X$ are sold at the same price $p_{j}(i)=p_{j}$ and produced in equal amounts $x_{j}(i)=x_{j}$. Hence the price index $P_{X j}$ simplifies to the following expression:

$$
P_{X j}=N_{j}^{\frac{1}{1-\sigma}}\left(\frac{\sigma}{\sigma-1}\right) C_{X j}
$$

Given the free entry condition and the total resource constraint, the number of varieties produced in equilibrium equals:

$$
N_{j}=\frac{M_{j} \Lambda_{j}}{\sigma F_{X j}} \int_{\bar{Z}_{j}}^{1} \exp \left(g_{X j} Z\right) d G_{j}(Z)
$$

The model is closed with the market clearing conditions in sector $Y:^{15}$

$$
\left[1-s\left(P_{X j}\right)\right] M_{j} \bar{W}_{j}=M_{j} \Lambda_{j} \int_{0}^{\bar{Z}_{j}} \exp \left(g_{Y j} Z\right) d G_{j}(Z)
$$

Substituting (9), (11) and (12) as well as $C_{X j}=\exp \left(g_{Y} \bar{Z}_{j}\right) / \exp \left(g_{X j} \bar{Z}_{j}\right)$ into (13) and simplifying, we obtain one implicit function $\Im\left(\right.$.) that defines the equilibrium cut-off value $\bar{Z}_{j}$ for each country as a function of the parameter values and the distribution of skills $G_{j}(Z)$ :

$$
\begin{aligned}
& \Im\left[\bar{Z}_{j}, g_{Y}, g_{X j}, \beta, \sigma, \theta, M_{j}, F_{X j}, G_{j}(Z)\right]= \\
& =\int_{0}^{\bar{Z}_{j}} \exp \left(g_{Y j} Z\right) d G_{j}(Z)-\left(\frac{1-\beta}{\beta}\right)^{\theta}\left(\frac{\sigma}{\sigma-1}\right)^{\theta-1}\left(\frac{\sigma F_{X_{j}}}{M_{j} \Lambda_{j}}\right)^{\frac{\theta-1}{\sigma-1}} \frac{\exp \left(\theta g_{g_{j}} \bar{Z}_{j}\right)}{\exp \left(\theta g_{X_{j}} \bar{Z}_{j}\right)}\left(\int_{\bar{Z}_{j}}^{1} \exp \left(g_{X j} Z\right) d G_{j}(Z)\right)^{\frac{\sigma-\theta}{\sigma-1}}=0
\end{aligned}
$$

\subsection{Market Size, Productivity and Factor Endowments in Autarky}

Equation (14) can be used to derive exact predictions. In particular, we focus on the effects of three key variables: the market size of each economy, the productivity differences between economies and the factor (skill) endowment of each economy (all considered to be exogenous), and analyze their effects on the specialization pattern of a country, its price level and its real wages. Given the parameter restrictions assumed above, $(\sigma>\theta>1$ and $\left.g_{X j}>g_{Y j}\right)$ and beginning with two identical countries, we are able to characterize the effects when we change

\footnotetext{
${ }^{15}$ By Walras' Law the clearing of market $Y$ ensures the clearing of market $X$ as well.
} 
those variables in one country relative to the other. We provide the intuition for each proposition in the text and relegate the details of the proof to Appendix A.

Proposition 1: Given countries $i$ and $j$, characterized by otherwise identical parameters, if country $j$ has a larger population than country $i\left(M_{j}>M_{i}\right)$, in autarky it would have a lower skill cutoff level $\bar{Z}$, it would be relatively more specialized in sector $X$, and would have a lower price index $P$ and higher real wages $W(Z) / P$ for workers of any skill level, relative to country $i$.

Intuitively, an increase in country size, $M_{j}$, results in an expansion of sector $X$ as a larger market allows for more varieties. This has the effect of reducing the price of the composite good $X, P_{X j}$, (inversely related to $N_{j}$ ). Consumers shift their expenditure towards good $X$ more than proportionally, so that the share spent in sector $X, s\left(P_{X j}\right)$, increases. Due to increased demand for their output, firms in sector $X$ can pay higher wages so that the unit $\operatorname{cost} C_{X}$ increases. The logarithmic wage schedule in sector $X$ shifts up while the wage schedule for sector $Y$ remains unchanged. This is represented in panel A of Figure 1 by the upward shift of the steeper portion of the wage schedule depicted in grey. The cut-off skill level shifts from $\bar{Z}_{0}^{A}$ to $\bar{Z}_{1}^{A}$ and some workers move from sector $Y$ to sector $X$. In addition to the upward shift of the wage schedule in sector $X$, since the overall price index decreases, the real wages of all workers increase. ${ }^{16}$

Proposition 2: Given countries $i$ and $j$, characterized by otherwise identical parameters, if country $j$ has larger absolute productivity than country $i\left(\Lambda_{j}>\Lambda_{i}\right)$, in autarky it would have a lower skill cutoff level $\bar{Z}$, it would be relatively more specialized in sector $X$, and would have a lower price index $P$ and higher real wages $W(Z) / P$ for workers of any skill level, relative to country $i$.

An increase in the average productivity $\Lambda_{j}$ has the same qualitative and quantitative effects as the increase in $M_{j}$ on the cut-off skill level $\overline{Z_{j}}$ and on the number of varieties, the price and the expenditure and production shares of $X$. In fact, the product $M_{j} \Lambda_{j}$ captures a country's "market potential". A larger market potential increases the expenditure on good $X$ more than proportionally, with the same effects explained above. The only difference with respect to an increase in $M_{j}$ is that the increase in the productivity term $\Lambda_{j}$ also has a direct impact on the entire wage schedule (see Equation 8). Graphically, in this case both the flatter and the steeper section of the logarithmic wage schedule (in units of $Y$ ) move up, with the shift of the steeper part being larger (as illustrated in Figure 1 Panel A by the shift of the grey lines). As a result, the cut-off skill level shifts from $\bar{Z}_{0}^{A}$ to $\bar{Z}_{1}^{A}$.

Proposition 3: Given countries $i$ and $j$, characterized by otherwise identical parameters, if country $j$ has a more productive technology in sector $X$ than country $i\left(g_{X j}>g_{X i}\right)$ then, as long as the parameter $\theta$ is close to one, in autarky it would have a higher skill cut-off level $\bar{Z}$, lower price index and it would be relatively more specialized in sector $X$. Real wages $W(Z) / P$ would also be higher for workers initially in sector $Y$ and for the

\footnotetext{
${ }^{16}$ Notice that in Figure 1 the logarithmic wage is represented in units of the numeraire $(Y)$. Hence the changes in the real wage due to changes in the overall price index $(P)$ are not reported.
} 
workers with skill level above a certain threshold.

An increase in the productivity of sector $X$ allows the same number of workers to produce more varieties of the good, increasing the relative supply of $X$. As the income and the supply of workers in $Y$ do not change this decreases the expenditure per unit of variety of $X$. Since there is now more competition in sector $X$, the skill level of the infra-marginal worker increases. This is illustrated in Figure 1 Panel B. Since the slope $g_{X j}$ increases, the logarithmic wage schedule in sector $X$ shifts down and tilts upward (depicted by the grey line), with the cut-off skill level increasing from $\bar{Z}_{0}^{A}$ to $\bar{Z}_{2}^{A}$. The increase in the number of varieties of $X$ decreases $P_{X}$ and, hence, the price index. This results in a larger share of income of country $j$ being spent in sector $X$, implying an increased relative specialization of the country in sector $X$. All workers who were initially in sector $Y$ (between 0 and $\bar{Z}_{0}^{A}$ in Figure 1 Panel B) receive higher real wages, as they experience no changes in their nominal wages but face a lower price index. Workers with skill levels above $Z^{*}$ in Figure 1 Panel $\mathrm{B}$ (the intersection of the new wage curve with the old one) benefit from the increase in nominal wages due to the increase in $g_{X j}$, as well as from the decrease in prices. Only workers with skills between $\bar{Z}_{0}^{A}$ and $Z^{*}$ (some of which move from sector $X$ to $Y$ ) may experience a decrease in real wages despite the decrease in the price index.

Proposition 4: Given countries $i$ and $j$, characterized by otherwise identical parameters, if country $j$ has a larger share of highly-skilled workers relative to country $i\left(G_{j}(Z) \leq G_{i}(Z)\right.$ for all $\left.Z\right)$, then in autarky it would have a higher skill cut-off level $\bar{Z}$, it would be relatively more specialized in sector $X$, and would have lower price index $P$ and higher real wages $W(Z) / P$ for workers in sector $Y$, though there is an ambiguous effect on the real wages of workers in sector $X$.

Consider the simple case in which we move some mass of workers from skill level $Z_{0}$ to skill level $Z^{\prime}>Z_{0}$, assuming that workers with skill $Z_{0}$ work in sector $X$ to begin with. In this case the productivity in sector $X$ as a whole increases and this in turn increases the supply of $X$ and the number of varieties produced, and decreases the price of $X$. This implies that the unit compensation for workers in sector $X, C_{X}$, decreases so that the logarithmic wage schedule in sector $X$ shifts down and the cut-off skill level $\overline{Z_{j}}$ increases. This corresponds to the parallel shift down of the steeper portion of the wage schedule (in grey) in Figure 1 Panel B. As the price index decreases, the real wages of workers in sector $Y$ increase. However, for any skill level, the real wages in sector $X$ may decrease or increase depending on the relative magnitude of the price effect compared to the decrease in the unit cost, $C_{X}$.

In matching the model to the empirical characteristics of the economies of Western and Eastern Europe we have the following: (i) a larger population in Western Europe, or Country 1 in our model $\left(M_{1}>M_{2}\right)$; (ii) higher absolute productivity in the West $\left(\Lambda_{1}>\Lambda_{2}\right)$; (iii) higher relative productivity of the West in sector $X$ 
$\left(g_{X 1}>g_{X 2}\right)$ and of the East in sector $Y\left(g_{Y 1}<g_{Y 2}\right){ }^{17}$ and (iv) a larger share of highly educated workers in the West, $G_{1}(Z)<G_{2}(Z)$ for all $Z$. Characteristics (ii) and (iii) reflect the overall productive advantage and the stronger "skill-bias" of the technology of more industrialized countries, as documented in recent work by Caselli and Coleman (2006). ${ }^{18}$ Hence, in light of Propositions 1 to 4, in autarky the West should exhibit lower prices and higher wages in units of the numeraire, especially for highly educated workers (due to features i, ii and iii) as well as greater specialization (income share) in sector $X$, relative to the East. As for the cut-off skill level $\overline{Z_{j}}$, characteristics (i) and (ii) would imply a larger value of $\overline{Z_{j}}$ in the East, while (iii) and (iv) would imply a lower value. In Figure 2 we represent the logarithmic real wage schedules in Country 1 (West) and 2 (East), namely $\ln \left(W_{1}(Z)\right)-\ln \left(P_{1}\right)$ in the upper panel and $\ln \left(W_{2}(Z)\right)-\ln \left(P_{2}\right)$ in the lower panel. As observed, the intercept (at $Z=0$ ) of the logarithmic wage is higher in the West relative to the East, due to its higher TFP and lower overall price index. Figure 2 also shows that the wage schedule is flatter below $\overline{Z_{j}}$ and steeper above it for the West relative to the East (that is, there exists a larger college-primary school wage premium in the West) with $\overline{Z_{j}}$ being slightly larger in the West. Finally, the largest cross-country real wage differentials are experienced by the highly educated workers.

\section{Opening to Trade and Migration}

Maintaining the assumptions on technology and preferences described above, in this section we analyze the effects of trade (section 4.2) and then migration (section 4.3). However, before considering trade liberalization, we discuss the incentives and potential effects of migration if labor mobility was to take place in a tradeless world. This is commonly done in the analysis of migration in cross-country models (as trade is essentially ignored) and serves as a useful reference point.

\subsection{Migration Patterns and Gains in the Absence of Trade}

The migration incentives are given by the differences, for each skill level $Z$, in the logarithm of real wages of each country (depicted in the upper and lower panels of Figure 2). As can be observed in Figure 2, in the absence of any type of migration costs and for plausible values of the parameters, the wage schedule of Country 2 (the East) is below that of Country 1 (the West) at any skill level. This means that all workers in the East would have economic incentives to migrate to the West. However, if we introduce migration costs, the real wage-schedule of Country 1, net of migration costs, would shift down. We show this in Figure 3 where the grey line represents

\footnotetext{
${ }^{17}$ We also assume that $F_{X 1}>F_{X 2}$. Intuitively, Country 1 uses a technology in sector $X$ that is more sophisticated and expensive (with a higher fixed cost) than the one used in Country 2, but it is also more productive, particularly when combined with highly skilled workers.

${ }^{18}$ More generally one could express the functions $A_{X j}(Z)$ and $A_{Y j}(Z)$ as $\Lambda_{j} f_{X j}(Z)$ and $\Lambda_{j} f_{Y j}(Z)$ with the restriction $\Lambda_{1}>\Lambda_{2}$ (reflecting a higher total factor productivity in Country 1) and the condition $\partial \ln f_{X 1}(Z) / \partial Z>\partial \ln f_{X 2}(Z) / \partial Z>\partial \ln f_{Y i}(Z) / \partial Z$, capturing the skill-bias of the technology in sector $X$ over that in sector $Y$ and the stronger skill-bias in Country 1.
} 
the real wage schedule of Country 2 while the black lines depict the real wage schedule in Country 1 net of migration costs. For ease of illustration, Figure 3 assumes that migration costs are a proportion $\delta$ of wages, so that the logarithmic wage schedule net of migration costs is a parallel shift down of Country 1's original real wage schedule. ${ }^{19}$ For $\delta$ close enough to $1\left(\delta_{\text {PROHIBITIVE }}\right)$ the negative shift is large enough as to put the migration cost-adjusted wage schedule of Country 1 below the wage schedule of Country 2 for all relevant skill levels. In this case there is no incentive for any worker to move. As migration costs decrease to $\delta_{H I G H}$ (see the intermediate black wage schedule in Figure 3) all workers above the threshold $Z_{0}^{\text {High }}$ would migrate, as their real wage in Country 1 net of migration costs would be higher than their wage in Country 2. Finally, given the shape of the wage schedules, if migration costs decrease further to $\delta_{L O W}$ (captured by the highest black wage schedule in Figure 3) migration patterns become V-shaped: those with very low skills (below $Z_{o o}^{\text {Low }}$ ) as well as those with high skills (above $Z_{o o}^{H i g h}$ ) would migrate. Workers with intermediate skill levels have the smallest (or no) incentives to migrate to Country 1 even when migration costs are low.

Considering the case of high migration costs (the most plausible scenario even if legal barriers to migration are substantially reduced), migration mainly increases the supply of highly educated workers in Country 1 and decreases that of Country 2. Based on Propositions 1 and 4 of section 3.5 this has the following effects:

1. The number of varieties of good $X$ produced in Country 1 increases and the price $P_{X}$ decreases. This has positive real wage effects for workers in sector $Y$. As for workers in sector $X$, they experience two effects: the same positive price effect and a negative competition effect, as their wage decreases relative to that of workers in sector $Y$. The overall effect on their real wages is ambiguous. Still, average wages in Country 1 increase unambiguously.

2. By contrast, in Country 2 the number of varieties of $X$ decreases and the price $P_{X}$ increases. Clearly, the real wages of workers in $Y$ decline, and using the same reasoning as before the effect on the real wages of the workers remaining in sector $X$ is ambiguous, while migrants leaving Country 2 increase their net real wage. Overall, the average real wages in Country 2 decrease.

In sum, in the absence of trade, the real wage effects of migration are positive for the migrants and for the receiving country overall and negative for the sending country, which loses its most educated workers and experiences an increase in the price index. The effect is particularly negative for the less educated workers remaining in the sending country. As we will see next, the consequences of migration are quite different when labor mobility takes place in conjunction with trade.

\footnotetext{
${ }^{19}$ In our simulations in Section 5 we consider more complex migration costs. They have a component proportional to wages and a fixed component. In this case, the (migration cost-adjusted) wage schedule of country 1 would shift down and slightly rotate counterclockwise, as fixed costs affect less skilled workers proportionally more. The qualitative implications, though, are similar to the case of proportional costs illustrated in Figure 3.
} 


\subsection{Trade}

Consider the two economies described in section 3 and allow them to trade with each other. For simplicity we will assume that good $Y$ is traded at no cost so that $p_{Y 1}=p_{Y 2}=p_{Y},{ }^{20}$ while we allow for iceberg-type trade $\operatorname{costs} \tau \geq 1$ for good $X$. The consumers in country $j$ can now buy varieties of good $X$ produced in either country. The demand in country $j$ for local and imported varieties (from $i$ ) are respectively:

$$
\begin{aligned}
x_{j j}=\left(\frac{s\left(P_{X j}\right)}{P_{X j}}\right)\left(\frac{p_{j}}{P_{X j}}\right)^{-\sigma} E_{j} \quad j=1,2 \\
x_{i j}=\left(\frac{s\left(P_{X j}\right)}{P_{X j}}\right)\left(\frac{p_{i} \tau}{P_{X j}}\right)^{-\sigma} E_{j} \quad i, j=1,2 \quad i \neq j
\end{aligned}
$$

where $p_{j}$ is the price of the varieties produced locally, and $p_{i} \tau$ is the price paid for imported varieties. Again, $s\left(P_{X j}\right)$ denotes the expenditure share that consumers in country $j$ devote to the composite good $X$ while $E_{j}$ is aggregate expenditure in country $j$ and, since the model has no capital accumulation, it equals total income: $E_{j}=W_{j}, j=1,2$. Finally, the price of the composite good $X, P_{X j}$, is given by:

$$
P_{X j}=\left[N_{j} p_{j}^{1-\sigma}+N_{i}\left(p_{i} \tau\right)^{1-\sigma}\right]^{\frac{1}{1-\sigma}} \quad i, j=1,2 \quad i \neq j
$$

On the production side, profit maximization yields the equilibrium price $p_{j}$ for each variety of good $X$ sold domestically and free entry determines the scale of production. The conditions are identical to those in (10) with the only difference that now the quantity of each variety produced in country $j$ is the sum of the demand at home and abroad, $x_{j}=x_{j j}+x_{j i} \tau$.

As in autarky, the skill threshold in each country, which determines the assignment of workers across sectors, $\bar{Z}_{j}^{T}$ (with the $T$ superscript denoting the equilibrium with trade), is given by an inter-industry wage equalization condition similar to (7). The value of these thresholds can be pinned down from the world market clearing conditions, namely the market clearing condition for the homogeneous good $Y$, for each variety of good $X$ produced in Country 1 and for each variety of good $X$ produced in Country 2 (see the equations in Appendix B).

\subsubsection{Costless Trade}

In order to identify the effects of trade it is useful to begin analyzing the particular case of costless trade (i.e., when $\tau=1$ ) as it yields simpler equilibrium conditions. In the next section we will explain how trade costs $(\tau>1)$ modify some of the effects of trade. The most important implication of free trade is price equalization across the border for each variety of good $X, p_{1}=p_{2}$, that in turn implies equalization of the unit costs

\footnotetext{
${ }^{20}$ This assumption ensures a common wage per unit of skill for workers in sector $Y$ in the two countries and simplifies the analysis considerably.
} 
$C_{X 1}=C_{X 2}=C_{X}$. Together with full access to all varieties from either country, this also implies equalization of the price of the composite good, $P_{X 1}=P_{X 2}=P_{X}$, and thus of the overall price index, $P_{1}=P_{2}=P$. This result simplifies substantially the two market clearing conditions for varieties of $X$ produced in each country (see Appendix B), which when divided by one another simplify to the following expression:

$$
\frac{\exp \left[\left(g_{X 1}-g_{Y 1}\right) \bar{Z}_{1}^{T}\right]}{\exp \left[\left(g_{X 2}-g_{Y 2}\right) \bar{Z}_{2}^{T}\right]}=\left(\frac{F_{X 1}}{F_{X 2}}\right)^{\frac{1}{\sigma}}
$$

while the market clearing condition for $Y$ becomes:

$$
\left[1-s\left(P_{X}\right)\right]\left(M_{1} \bar{W}_{1}+M_{2} \bar{W}_{2}\right)=M_{1} \Lambda_{1} \int_{0}^{\bar{Z}_{1}^{T}} \exp \left(g_{Y 1} Z\right) d G_{1}(Z)+M_{2} \Lambda_{2} \int_{0}^{\bar{Z}_{2}^{T}} \exp \left(g_{Y 2} Z\right) d G_{2}(Z)
$$

Proposition 5: Relative to autarky, in free trade Country 1 specializes in the production of the differentiated good $X$ while Country 2 specializes in the production of $Y$, i.e., $\bar{Z}_{1}^{T}<\bar{Z}_{1}^{A}$ and $\bar{Z}_{2}^{T}>\bar{Z}_{2}^{A}$.

Proof: Country 1 has a more productive technology in sector $X$ than Country 2 (i.e., $g_{X 1}>g_{X 2}$ ) and is relatively abundant in highly educated workers. By Propositions 3 and 4 above, this implies that in autarky $C_{X 1}<C_{X 2}$ and $p_{1}<p_{2}$. The convergence in prices under free trade implies a relative increase in $p_{1}$ (and thus $\left.C_{X 1}\right)$ so that the threshold level $\bar{Z}_{1}$ decreases. This means an increase in the share of workers in sector $X$. The opposite happens in Country 2 where a lower value of $C_{X 2}$ implies a lower logarithmic wage schedule for sector $X$ and an increase in $\bar{Z}_{2}$ relative to autarky.

Corollary: Under free trade, the larger the comparative advantage of Country 1 in sector $X$ (i.e., the larger the ratio $\left.\frac{\left(g_{X 1}-g_{Y 1}\right)}{\left(g_{X 2}-g_{Y 2}\right)}\right)$, the larger the share of workers of Country 1 engaged in sector $X$, relative to Country 2 . That is, a lower value of $\bar{Z}_{1}^{T}$ relative to $\bar{Z}_{2}^{T} \cdot{ }^{21}$

Figure 4 shows the shift in the logarithmic real wage schedule from autarky (black line) to the equilibrium with costless trade (grey line). Two effects take place. First, as stated in Proposition 5 there is an expansion of sector $X$ in Country $1\left(\bar{Z}_{1}^{T}<\bar{Z}_{1}^{A}\right)$ and an expansion of sector $Y$ in Country $2\left(\bar{Z}_{2}^{T}>\bar{Z}_{2}^{A}\right)$. Hence, trade liberalization leads to an increase in the relative wages of workers of sector $X$ in Country 1 and a relative decrease of those wages in Country 2 (the typical Stolper-Samuelson effect). Even with full price convergence and higher relative efficiency of Country 2 in producing good $Y$ there need not be full specialization of Country 2 in free trade. This is because, due to the heterogeneity of workers, those with very high skills are relatively more productive in sector $X$, also in Country 2, and would rather work in that sector. This is true unless the technological differences between countries in sector $X$ are large enough $\left(g_{X 1}>>g_{X 2}\right)$ as to generate an international equilibrium price of $X$ low enough so that even the most skilled worker in Country 2 (with $\bar{Z}=1$ )

\footnotetext{
${ }^{21}$ See the proof in Appendix B.
} 
would rather work in sector $Y .{ }^{22}$ Moreover, due to the increase in varieties, the common price level, $P$, in free trade is lower than the prices of each country $\left(P_{1}\right.$ and $\left.P_{2}\right)$ in autarky. This implies a parallel shift up of the real wage schedules in both countries. In Figure 4 (as in the simulations of section 5.2.1) the upward shift of the real wage schedule in Country 2 is large enough that even workers in sector $X$ gain in real terms.

\subsubsection{Costly Trade}

With costly trade the extent to which each country can exploit its comparative advantage is reduced. The convergence in prices is only partial and thus the benefits derived from trade are more limited than under free trade. As for the productive specialization patterns, non-zero trade costs reinforce the "home market" effect which allows the large country to host a disproportionately larger number of firms in sector $X$. In particular, this home market effect is larger for intermediate trade costs, as zero costs eliminate the home market effect and prohibitive costs eliminate the foreign demand. So, beginning from high values, as trade costs decrease comparative advantage and the home market effect first operate in the same direction, namely increasing Country 1's specialization in sector $X$. This specialization reaches a maximum for some intermediate value of trade costs and as trade costs decrease to values close to zero the home market effect becomes less relevant and only comparative advantage is left.

Figure 5 plots the specialization patterns of each country (measured by the share of workers in sector $X$ ) against trade costs. The graph features the simulation results based on the parameter values used in section 5 to match the features of Western and Eastern Europe. At very high trade costs, the patterns of specialization approach those in autarky (with employment shares in sector $X$ of $34 \%$ and $28 \%$ in Country 1 and 2, respectively). With free trade $(\tau=1)$ the relative specialization of Country 1 in sector $X$ is stronger than in autarky (36\% of workers in sector $X$ compared to $22 \%$ in Country 2 ). However, the maximum relative specialization is reached around $\tau=1.3$ when $38 \%$ of the employment in Country 1 (and only $5 \%$ in Country 2) is engaged in sector $X$. For the parameter configuration used we also observe that Western Europe (Country 1) is very far from full specialization (in sector $X$ ) while for some intermediate values of trade costs Eastern Europe (Country $2)$ is not too far from complete specialization in sector $Y$.

\subsection{Trade and Migration}

Suppose that in addition to trade Countries 1 and 2 allow the movement of workers across the border. The equilibrium is characterized as before with only some modifications in order to accommodate the phenomenon of migration. For the sake of brevity we relegate to Appendix $\mathrm{C}$ the equilibrium conditions determining the threshold skill levels between sectors $X$ and $Y$ in each country, the expression for prices, and the number of

\footnotetext{
${ }^{22}$ In this case, trade liberalization would lead to complete specialization of Country 2 in sector $Y$.
} 
varieties and wages, and focus here on the patterns of migration.

Migration is not free but entails three types of costs: those due to the loss of skills, the psychological costs of living away from the country of origin and those generated by the legal barriers to international migration. Migrants suffer a loss in their human capital since part of their skills, such as language, knowledge of the local laws, norms and networks are specific to their country of origin. Consequently, we assume that a worker who moves to another country is subject to a permanent productivity loss of a fraction $\delta_{H} \in(0,1)$ of her wage relative to a native of comparable education. The psychological costs of migration, on the other hand, do not translate in a reduction in productivity but they decrease the utility that a worker derives from migrating. Translating this utility reduction in consumption-equivalent terms, we model such costs as a percentage reduction $\delta_{P} \in(0,1)$ in the real income (but not the productivity) enjoyed by the migrants. Finally, we consider the costs associated with the legal restrictions on international mobility. They are harder to model, yet it is obvious that for several skill groups those costs are close to being prohibitive (which eliminates altogether the possibility of migrating) and even when they are not prohibitive they entail a significant amount of resources that are "wasted" or unproductive. It is not clear whether legal costs of migration should be considered as proportional to wages or as fixed costs. If we think of the legal barriers as the paperwork, security checks and all the costs associated with the process of obtaining a working visa and settling in the foreign country, which all migrants experience, it seems reasonable to consider them as fixed costs. In our simulations in section 5.2.2 we consider legal costs as a fixed cost, $D_{B}$, independent of the skill level of the individual. ${ }^{23}$ In sum, the migration costs described above are modeled as a reduction by a fraction $\delta=\left(\delta_{H}+\delta_{P}\right)<1$ in the consumption wage enjoyed by the migrants plus a fixed $\operatorname{cost} D_{B}$. It is important to notice that even if a large part of the legal barriers to international migration $\left(D_{B}\right)$ were to be removed, the remaining human capital losses and psychological costs would still prevent perfect mobility.

The migratory patterns between Countries 1 and 2 are dictated by the cross-country real wage differences at each skill level. Figure 3 is still valid in illustrating qualitatively the migration incentives in the presence of trade.

Proposition 6: For migration costs lower than the prohibitive level, workers with skill levels higher than a threshold $\bar{Z}_{2}^{T M H}$ will migrate from Country 2 to Country 1. All the immigrants (except for the marginal one) will receive a production and consumption wage, net of costs, higher than they would receive in Country 2 . The cut-off skill level $\bar{Z}_{2}^{T M H}$ is given by the condition of equalization of (migration-cost adjusted) real wages across

\footnotetext{
${ }^{23}$ If, on the other hand, legal costs hamper the possibility of transferring schooling degrees and certifications, or if they generate a disadvantage in the search for jobs, they are likely to be better captured by a proportional factor (since they then take the form of a foregone share of wages). In Iranzo and Peri (2007) and in simulations (available upon request) we show the effect of reducing legal migration costs when they are proportional to wages. The qualitative effects are very similar to those illustrated in this paper with fixed legal costs.
} 
countries:

$$
\frac{W_{2}\left(\bar{Z}_{2}^{T M H}\right)}{P_{2}}=\frac{\left[1-\left(\delta_{H}+\delta_{P}\right)\right] W_{1}\left(\bar{Z}_{2}^{T M H}\right)-D_{B}}{P_{1}}
$$

Proof: Figure 3 provides the graphical proof that for high migration costs the real wage schedule in Country 1 net of immigration costs (intermediate black schedule) is above the real wage schedule in Country 2 (the grey schedule) for $Z>\bar{Z}_{2}^{T M H}$ (defined by equation 19 and represented in Figure 3 by value $Z_{o}^{h i g h}$ ). Hence, for high migration costs, only highly educated workers in Country 2 will migrate.

Proposition 7: For low migration costs, but still large enough so that not all workers migrate out of Country 2, workers with skills higher than threshold $\bar{Z}_{2}^{T M H}$ and workers with skill levels below a threshold $\bar{Z}_{2}^{T M L}$ would migrate to Country 1. Both thresholds are determined by a wage equalization condition similar to (19).

Proof: Figure 3 provides again the representation of the relevant real wage comparison. The highest black schedule in Figure 3 represents the migration cost-adjusted real wages in Country 1 when migration costs are low. As observed, it crosses the real wage schedule of Country 2 twice. $^{24}$ The lower crossing point defines $\bar{Z}_{2}^{T M L}$ and the higher crossing point defines $\bar{Z}_{2}^{T M H}$. Workers with skills below $\bar{Z}_{2}^{T M L}$ and those with skills above $\bar{Z}_{2}^{T M H}$ experience a real wage gain by moving from Country 2 to Country 1.

These patterns of migration are similar to those already described in the scenario of migration and no trade (section 4.1). What is different now is that, thanks to trade, the gains from migration are shared by the two countries and accrue to each group, while in the scenario with no trade they were confined to Country 1. Focusing on the case of high migration costs, represented in Figure 6, we first summarize the effects of migration under free trade (as it is clearer and easier to understand). Then we comment on the effects of migration with costly trade which is the case we simulate in section 5.2 .2

1. All migrant workers experience real wage gains and the total production of good $X$ increases.

As for Proposition 7, all workers with skills higher than $\bar{Z}_{2}^{T M H}$ earn higher wages, net of migration costs, in Country 1 and have higher productivity than in their country of origin. Thus the total combined production of good $X$ increases.

\section{Price levels decrease in both countries.}

As the total production and the number of varieties of $X$ increase, its price $P_{X}$, and thus the overall price index, decreases. ${ }^{25}$ Thanks to trade, workers in both countries benefit from the increased variety at lower prices.

\section{Less educated workers in both countries experience an increase in real wages.}

\footnotetext{
${ }^{24}$ When part of the migration costs are fixed, as in the present case, in order to ensure that a portion of the wage schedule in Country 1 is flatter than in Country 2 the fixed component should not be too large. In our simulation, the case with a double intersection of the wage schedules occurs for very low legal costs.

${ }^{25}$ With free trade, the reduction will be the same in both countries and if trade is costly, the decrease in $P_{X}$ will be smaller with $P_{X 1}$ decreasing more than $P_{X 2}$.
} 
The wages of less educated workers, in terms of $Y$, are determined by the productivity parameters, which do not change with migration. However, as a consequence of the decrease in the price index, workers in both countries experience an increase in their real wages. As for the workers in sector $X$ in Country 1, they will experience a decrease in their wage in units of the numeraire, but the drop in the price index will compensate (partially or totally) the wage decrease in real terms.

Figure 6 illustrates the change in the wage schedules going from free trade (black schedule) to free trade and migration (grey schedule) in the case of high migration costs. The highly educated in Country 2, with skills above $\bar{Z}_{2}^{T M H}$, move to Country 1 and sector $X$ disappears from Country 2. The dashed wage schedule in grey indicates that no worker in that skill range is left in Country 2 earning that potential wage. At the same time, the upward shift of real wages, due to the reduction in the price level (point 3 above), implies that each native of Country 2 is better off. The highly educated receive higher real wages when they migrate to Country 1 and the less educated who remain in Country 2 experience a real wage increase. Only the highly educated in Country 1 experience a decrease in real wages due to the competition effect from immigrants.

The effects of migration with costly trade are intermediate between the one with free trade described above and the one with no trade described in section 4.1. In particular, in Country 2 the loss of highly educated workers reduces the number of varieties produced domestically. However, their higher productivity abroad increases the number of varieties available internationally. As those varieties are imported by Country 2 at a cost, the relative size of productivity differentials in sector $X$ together with the magnitude of trade costs determine whether the net effect of migration on real wages (via price levels) of Country 2 is positive or negative. Clearly as the effect is positive in free trade and negative with no trade (prohibitive trade costs), there must be a level of trade costs below which the net effect of migration is positive and negative above it. Thus, ultimately whether this effect is positive or negative is an empirical question. Our simulations for Eastern and Western Europe in Table 4 use the actual productivity differentials and the estimated trade costs $(\tau=1.4)$ between the two regions. They show that allowing migration would produce an increase in the overall production of good $X$, a decrease of the price levels in both countries and an increase in the real wages of less educated workers in both countries. This means that for the observed trade costs and productivity differentials prevailing in Europe around 2000 the qualitative implications of freer worker mobility in the model with trade costs are similar to those for the model with free trade.

\section{Economic Integration between Eastern and Western Europe}

The case of Western (EU-15) and Eastern European countries is an interesting example of two regions that have moved, over approximately 20 years, from essentially no economic interaction with each other (up until 1989) to trade liberalization and to the elimination (by 2011) of legal restrictions to labor mobility. During the 1990s 
several Trade Agreements between Western and Eastern European countries were signed culminating with the entry in 2004 and 2006 of 10 Eastern European countries to the E.U. ${ }^{26}$ Trade liberalization, however, was not accompanied by the liberalization of labor markets as most Western countries kept in place clauses allowing them to restrict immigration from the East until $2011 .{ }^{27}$ As the transitional restrictions on labor mobility phase out, migration from the East to the West may increase substantially. In this section we use the model to predict how much migration is to be expected and with what consequences. We start by describing the parameterization of the model in section 5.1, while section 5.2 presents the simulations.

\subsection{Parameterization of the Model}

Table 2 summarizes the parameterization of the model. The values of the parameters are either obtained from the data or calibrated to reproduce the features of Eastern and Western European economies. Workers' skills, $Z$, are measured as years of schooling. We re-scale this variable so that it ranges from 0 (no schooling) to 1 (corresponding to a Doctorate degree, obtained after 20 years of schooling). Hence, one year of schooling equals 0.05 units of $Z$. Measuring skills with years of schooling has several advantages. First, comparable schooling data for Eastern and Western European countries are available from the Barro and Lee (2001) dataset beginning in the 1980s. Second, the Mincerian regression approach to wages finds that the natural logarithm of individual wages is a linear function of years of schooling. This is consistent with the wage schedule implied by our model. Third, particularly since the 1990s the returns to schooling for the highly educated in rich economies like Western Europe have been larger than those for the less educated. This also matches well our characterization of the wage schedule: flatter for low values of $Z$ and steeper for high values of $Z$. We use the schooling distributions in the year 2000 for Germany as representative of the average EU-15, and Poland as representative of the Eastern European members. We consider four educational groups according to the highest educational level achieved: less than primary education, primary education, secondary education, and college degree or more. Table 2 reports the share of the population in each of the four schooling groups in the early 1990s which we use to define the skill distribution for Western Europe $\left(G_{1}(Z)\right)$ and Eastern Europe $\left(G_{2}(Z)\right)$.

The parameters $g_{X j}$ and $g_{Y j}$ characterize the technologies employed in sectors $X$ and $Y$, respectively. They can be empirically inferred from the logarithmic wage schedules using equation (8). The parameter $g_{Y j}$ equals the returns to schooling of less educated workers (to the left of $\bar{Z}_{j}$ ) while $g_{X j}$ equals the returns to schooling for highly educated workers (to the right of $\bar{Z}_{j}$ ). Our calibration is based on data on returns to education from previous studies, particularly Caselli and Coleman (2006) and Psacharopoulos and Patrinos (2004) ${ }^{28}$. The

\footnotetext{
${ }^{26}$ These were Poland, Hungary, Czech Republic, Slovakia, Slovania, Lithuania, Latvia, Estonia (which entered the EU in 2004), Bulgaria and Romania (which entered in 2006).

${ }^{27}$ The only EU countries that allowed free labor mobility from the beginning were the UK, Ireland and Sweden.

${ }^{28}$ They collected data on average returns to schooling from Mincerian regressions for several countries. We combine those two studies to calibrate $g_{Y j}$ and $g_{X j}$ for Western Europe (Germany) and Eastern Europe (Poland). More precisely, we calibrate $g_{Y j}$ and $g_{X j}$ so that:
} 
values obtained are reported in Table 2. Consistent with our assumptions, the Mincerian estimates show that i) returns to skills are higher in sector $X$ than in sector $Y$ for both countries, ii) returns to skills in sector $X$ are larger in Western Europe while returns to skills in sector $Y$ are larger in Eastern Europe. We choose the total factor productivity (TFP) levels, $\Lambda_{j}$, and the fixed cost parameters, $F_{X j}$, to match the per capita income differential between East and West Europe at the end of the 1980s, and to ensure a cut-off skill level in autarky, $\bar{Z}_{j}^{A}$, around 12 years of schooling (secondary degree) for Eastern Europe and a little higher, (some college), for Western Europe. Normalizing $\Lambda_{2}=1$, this implies $\Lambda_{1}=2$. These parameters deliver an autarky equilibrium where the real per capita income of Eastern Europe is 0.37 times that of Western Europe, which matches the per capita income differential between Eastern and Western Europe as of $1989 .{ }^{29}$ We consider the late 1980s as representative of the "autarky" case. The population of working age (16 to 65 years of age) in Eastern Europe was around one third of the working age population of the Western European countries as of 1989 and since then the two blocks have followed similar demographic trends. This implies $M_{1}=1$ and $M_{2}=0.3$.

The rest of the parameters are assumed to be common to both regions and are reported in the lower part of Table 2. The parameter $\theta$, which measures the substitutability between goods $X$ and $Y$, is equal to the substitutability between workers that produce those goods (namely, more and less educated workers). The consensus estimate for this elasticity in the literature is around 1.5 (see Katz and Murphy 1992, and Ciccone and Peri 2005). The value of $\sigma$ captures the degree of substitutability between varieties of good $X$. This is an important parameter as the magnitude of the gains from trade due to new varieties depends (inversely) on this parameter. Broda and Weinstein $(2004,2006)$ produced several estimates of the elasticity of substitution between differentiated varieties in 3-digit SITC sectors which would correspond to $\sigma$. We choose a value of $\sigma=4$ as the baseline specification (their mean value) ${ }^{30}$ and conduct robustness checks for values of $\sigma$ between 3 and $\infty .{ }^{31}$ The parameter $\beta$ is chosen to be around 0.5 , which delivers an expenditure share for good $X$ in autarky of 0.42 , close to the expenditure share on differentiated high-tech goods in Western Europe in the early 1990s. ${ }^{32}$

\footnotetext{
- The wage premia of workers with "college completed" vs. those with "primary completed only" equal the premia estimated by Caselli and Coleman (2006) for Germany and Poland.

- The yearly Mincerian returns for Germany and Poland, obtained as an average of the returns to schooling of the low and highly educated (where the highly educated group is defined as those with a High School diploma or more), match the average returns reported in Psacharopoulos and Patrinos (2004).

${ }^{29}$ Based on data from the Penn World Tables. Hall and Jones (1999) report similar numbers: the ratio of output per worker in West Germany relative to Hungary in the late 1980s was 0.36 and the ratio of output per worker in France relative to Poland was 0.33 .

${ }^{30}$ The value of $\sigma=4$ also roughly coincides with the mean estimate of the elasticity of substitution for the 4-digit SITC- sectors that Rauch (1999) classifies as differentiated goods.

${ }^{31}$ Available from te authors upon request.

${ }^{32}$ We calculate the consumption share in differentiated goods using the Eurostat Statistics 3-digit consumption classification as follows. Out of all tradeable goods and services (ie, excluding construction and real state, education, health and hotel services) we consider food and beverages, clothing and apparel as homogeneous, and all the others (medical products, vehicles, audio-visual and information processing equipment, furnishings and home equipment, etc.) as differentiated.
} 


\subsection{Simulations: the Effects of Trade and Migration}

Following the theoretical approach, we begin with the scenario of autarky and analyze first the effects of trade liberalization only (section 5.2.1) and then the effects of relaxing the legal restrictions to labor mobility (section $5.2 .2)$.

\subsubsection{Trade Liberalization and no Migration}

The first two columns of Table 3 report the values of the most relevant variables in the autarky equilibrium (specification I) and under free trade (specification II) for Western and Eastern Europe. For ease of comparison, we standardize to one the price level and the per capita GDP in Western Europe in autarky. In the autarky equilibrium the real income per capita in Eastern Europe was $37 \%$ that in the West (matching the data in 1989 ) and the price index in Eastern Europe was 34\% higher than in Western Europe. As for the productive specialization, 34\% of the workers in Western Europe and only 28\% of Eastern Europe worked in the high-tech differentiated sector $X$. The difference in specialization is not too large because in autarky each country needs to produce all of its consumption goods. The four rows in the mid-section of Table 3 report the real wages of workers by educational group. ${ }^{33}$ In autarky, workers of any schooling level in Eastern Europe are paid less than in Western Europe; even the college educated in the East do not reach the real wage of the least educated in Western Europe. The large productivity and price level differentials are the reasons for these wage differences.

With respect to the autarky scenario, trade liberalization introduces three significant changes. First, prices tend to converge and, in Specification II with free trade, there is complete price equalization between East and West. Second, the change in relative prices induces countries to specialize in the production of the goods in which they enjoy a comparative advantage. Western Europe increases its relative employment in sector $X$ (under free trade $36 \%$ of the labor force works in that sector versus $34 \%$ in autarky) while the East increases its employment in sector $Y$ ( $81 \%$ of the labor force works in $Y$ under free trade while only $72 \%$ in autarky). Third, more varieties of $X$ are produced and consumed and, in the case of free trade, at a lower price in both countries, so that the overall price level decreases. Notice that it decreases much more in the East (going from 1.34 to 0.99, experiencing a $26 \%$ decrease) than in the West (where it goes from 1 to 0.99 experiencing only a $0.8 \%$ decrease) relative to the autarky price, because the East gains access to a much larger basket of new differentiated goods. In terms of real wages, two effects take place. On the one hand, trade has the typical Stolper-Samuelson effect, increasing the relative wages of the high-skilled workers in the West (where the college-primary school premium increases from 1.81 to 2.07) and those of the low-skilled in the East (where the college-primary school premium decreases from 1.65 to 1.60). Moreover, there are benefits to all groups of workers from the decrease in the price of the differentiated good $X$ (the gains from variety). This second effect is large enough so that in terms of real

\footnotetext{
${ }^{33}$ Always standardized by the autarky per capita income of Western Europe.
} 
wages each single group gains. As indicated by the per capita real income (in the second row) both countries gain, on average, from trade. The gains, however, are much larger for Eastern Europe $(+34 \%)$ than for Western Europe $(+1.9 \%)$.

Trade liberalization between Eastern and Western Europe was largely achieved by 2004. Hence, we are able to check whether our model's predictions match the actual data in 2004 (which is also the most recent year for which most data is available). In particular, we check the predicted convergence in real income per capita, the predicted volume of trade between East and West Europe and the predicted composition of trade between goods $X$ and $Y$. The prediction on the composition of trade (non-differentiated, traditional goods, $Y$, and differentiated goods $X$ ) is very important because the gains from variety depend largely on the volume of differentiated trade. We use the popular classification of non-differentiated and differentiated goods introduced by Rauch $(1999)^{34}$ and compute the share of trade in differentiated goods between East and West Europe for the year 2004. Column II of Table 3 shows that under free trade the predicted volume of trade between the two economies is about $10 \%$ of their joint GDP (reported in the second to the last row) and the share of trade in differentiated goods is around $78 \%$ (reported in the last row). The simulations also predict an increase in Eastern European per capita income to almost $50 \%(0.487=0.496 / 1.019)$ of the Western income per capita. The actual data for 2004 shows that the bilateral volume of trade was $9 \%$ of total European tradeable GDP, ${ }^{35}$ the share of differentiated trade amounted to $77.9 \%$ according to what Rauch (1999) calls a "liberal" classification and $81.5 \%$ according to a "conservative" classification, while the income per capita in the East was equal to $42 \%$ of that in Western Europe. ${ }^{36}$ So the model with no trade costs slightly over-predicts the volume of trade and the real per capita income convergence and predicts exactly the split of trade between differentiated and non-differentiated goods.

Using the degree of freedom provided in the model by trade costs, $\tau$, we use it to match the predicted volume of trade to the actual volume ( $9 \%$ of European tradeable GDP). The results are reported in the specification with Costly Trade in Column III of Table 3. The "calibrated" value of trade costs is $40 \%$ of the traded value (i.e., $\tau=1.4)$. This is not unreasonable if we consider that it includes transport costs as well as all the bureaucratic hurdles, non-tariff barriers, and difficulties associated with trade in services. ${ }^{37}$ In terms of income per capita, the simulated value for Easter Europe in column III is $0.42(=0.426 / 1.014)$ times that in Western Europe, which

\footnotetext{
${ }^{34}$ We thank Jim Rauch for kindly making that classification available to us. According to the classification, non-differentiated traded goods are those sold in organized world markets that therefore have worldwide quoted or reference prices, while differentiated goods are those for which no worldwide quoted or reference prices exist.

${ }^{35}$ Tradeable GDP is calculated using the OECD National Accounts data for Europe in 2004 which disaggregates total gross value added into 6 sectors: 1) Agriculture, hunting, forestry and fishing; 2) Industry, including energy; 3) Construction; 4) Wholesale and retail trade, repairs, hotels and restaurants, and transport; 5) Financial intermediation, real estate, renting and business activities; 6) Other service activities. We consider the first 2 sectors as tradeable, which account for about a third of total value-added, and the rest as non-tradeable. We are aware that this criterion understates the share of tradeable GDP as some of the goods and services in the excluded sectors, such as some financial and business services, are traded across the border. However, the lack of more disaggregated sectoral data impedes us to obtain a more accurate share of tradeable GDP. Therefore, the figure of $9 \%$ should be considered as an upper bound for the ratio of non-tradeable to tradeable GDP.

${ }^{36}$ Calculated using GDP data for European countries from the Penn World Tables.

${ }^{37}$ According to Hummels (2007), freight costs for most tradeable goods are close to $10 \%$ of their value.
} 
matches exactly the ratio measured in 2004. This income convergence is achieved through an increase in real per capita income, with respect to autarky, by $1.4 \%$ for Western Europe and by $15.3 \%$ for Eastern Europe (more moderate than in the case of no trade costs). Essentially, the entire real income convergence from 1989 to 2004 could be explained by the effect of trade (we kept TFP constant at its pre-trade levels). Finally, in the scenario with costly trade, the simulated share of trade in differentiated goods equals $54 \%$, which is smaller than with free trade and under-predicts the actual figures (77.9-81.5\%). This is in part due to the fact that trade costs are imposed only on sector $X$ and thus they reduce relatively more the trade in differentiated products. If anything, though, our model under-predicts the volume of (and therefore the benefits from) differentiated trade when we simulate the case of costly trade.

An interesting feature of the model with costly trade, confirming the findings of section 4.2 .2 , is that trade costs result in starker specialization patterns. Due to the stronger home market effect, Western Europe specializes more in sector $X$ relative to the case with costless trade (38\% of the labor force rather than $36 \%$ ), while Eastern Europe specializes more in sector $Y(96 \%$ of the labor force rather than $81 \%)$.

\subsubsection{Trade and Labor Mobility}

Migration from Eastern to Western Europe began during the 1990s, yet restrictions on labor mobility, in the form of laws, insider privileges and bureaucratic barriers, still exist. The last row of Table 1 shows the emigration rates by educational level in Eastern Europe in 2000. As can be observed, the emigration rate of the highly educated is three to four times that of other groups. Our model can easily explain this phenomenon: highly educated workers have the largest incentives to migrate and, in the presence of high barriers to international labor mobility, they are the only group migrating.

Specification I of Table 4 shows the case where labor mobility is allowed and total migration costs are calibrated so as to generate the migration rate of highly educated Eastern European workers as reported by Docquier and Marfouk (2005)- that is, equal to 14\%. ${ }^{38}$ The last row of the table reports the overall emigration rate (emigrants/sending country residents) which equals 1.48\% of the Eastern European population of working age and its split between highly skilled (secondary education or more) and less skilled (primary education or less). In this case all migrants have college education or more so the split is $100 \%$ and $0 .{ }^{39}$ The corresponding values for Western Europe report the immigrants flow relative to the labor force of Western Europe. This constitutes an immigration rate (immigrants/receiving country residents) of $0.44 \%$. Migration costs are calibrated as follows. The value of $\delta_{H}$, the (percentage) human capital loss, is based on Friedberg (2000) who estimates wage losses from immigrants to Israel (many of them from Russia and Eastern Europe) of 25\%, relative to similar natives.

\footnotetext{
${ }^{38}$ While emigration rates in the other education groups are not 0 , they are small enough as to make this a reasonable approximation.

${ }^{39}$ The overall percentage of $1.48 \%$ is obtained as the product of the emigration rate of highly educated workers (14\%) times the share of highly educated (skilled) workers in the total Eastern European laborforce (about 10.5\%).
} 
We thus set $\delta_{H}=0.25{ }^{40}$ The value of $\delta_{P}$, the (percentage) psychological cost, is empirically inferred from actual migration rates in cases with unrestricted international mobility. There have been periods in history with virtually no legal restrictions on labor mobility between some countries but still large wage differentials. For instance, Puerto Ricans have had full citizenship rights in the U.S. since 1945 and average wages in Puerto Rico are around $25 \%$ of those in the U.S. Yet we observe in those instances that migration falls short of what we would expect based on economic considerations. Thus Puerto Rico had an emigration rate during the 1950s and 1960 s of only $0.8 \%$ each year and about $35 \%$ over thirty years. ${ }^{41}$ Although these figures are substantial, they also indicate that despite the large differences in per capita income and no legal barriers to migration, the large majority of people did not migrate-the stock of Puerto Ricans in the U.S. in 2000 was around $33 \%$ of the population of Puerto Rico. Klein and Ventura (2006) calibrate the psychological costs as the costs needed, on top of human capital costs, to generate an average yearly migration rate equal to $1 \%$ per year over 25 years. They obtain a "utility cost" that, expressed in consumption-equivalent terms, amounts to a loss of between 15 and $20 \%$ of the steady state real wage. ${ }^{42}$ Given that migration rates of $1 \%$ per year are among the highest observed, this range is probably a lower bound for psychological costs and so we use the value of $\delta_{P}=0.20$ as reference. Finally, we do not have empirical estimates for the costs implied by the existing legal barriers between East and West, $D_{B}$. However we calibrate these residual legal costs in order to deliver the migration rates observed in 2000 . These legal costs would have to be equal to an additional $26 \%$ reduction on the wages that highly educated migrants would receive in the West. Thus, Column I of Table 4 shows the equilibrium corresponding to the scenario with such calibrated legal migration costs and trade costs equal to $\tau=1.4$. Notice that, given the small migratory flows, the scenario of Column III in the previous Table 3 is similar to the one of Column I in Table 4: the current situation corresponds to a situation of relatively free trade and highly constrained labor mobility.

Specifications II and III of Table 4 analyze the effects of reducing the existing legal barriers to migration $\left(D_{B}\right)$ and show some of the key contributions of our analysis. In particular, specification II shows the case where the costs of legal barriers to migration have been reduced to half of their current value (intermediate migration costs, equal to $13 \%$ of the wage received by migrants to Western Europe) while column III considers the scenario where most legal restrictions to labor mobility have been removed. ${ }^{43}$ In both cases we keep the

\footnotetext{
${ }^{40}$ Based on Mexican immigrants to the U.S., Borjas (1996) estimates earning losses of around $15 \%$. This smaller percentage is likely to be affected by the skill composition of migrants. Since a large fraction of them were low skilled and employed mostly in manual jobs, their loss of ability is likely to be proportionally smaller than that of more educated workers employed in occupations where language and knowledge of local norms is more important.

${ }^{41}$ Hatton and Williamson (2005), (2006) report similar migration rates from Italy, Ireland and Poland to the US in the period 1880-1913.

${ }^{42}$ We thank Gustavo Ventura for making available to us the average psycological cost in utility-equivalent terms implied by the Klein and Ventura (2006) model applied to the US-Mexico case.

${ }^{43}$ Examples of the minimum administrative costs that might still remain are the information costs and paperwork needed to get access to the Social Security, medical and tax systems, among others, in the destination country. We do not claim that these minimum costs are equal to $17 \%$ of the current legal costs - in fact, it's reasonable to believe they are higher. In terms of wages this level of migration costs corresponds to $4 \%$ of the wage that immigrants receive in the West.
} 
human capital and psychological costs constant. The scenario with intermediate migration costs is probably the most realistic, while the scenario with low costs seems a limiting case.

As migration costs are reduced several interesting effects can be observed. First, the increased migration increases the relative specialization between East and West: for intermediate migration costs (specification II), the East completely specializes in sector $Y$ (see employment shares). Second, the migration-threshold for Eastern European workers in specification II corresponds to workers with completed secondary education. ${ }^{44}$ That is, with intermediate costs only workers with secondary and tertiary education migrate, which results in a total migration rate of less than $9 \%$ of the Eastern European labor force. In contrast, specification III (with low migration costs) illustrates the case where there is migration at the top (secondary education and above) and at the bottom (less than primary education) of the schooling distribution. Interestingly, this case produces a total emigration rate from Eastern Europe around 30\%, a value that is in line with the historical long-run emigration rates from Puerto Rico to the U.S. during the period 1950-2000. Third, despite the increase in the relative specialization of the regions, the volume of trade (not reported in the Table) decreases as migration costs are reduced (from the current $9 \%$ of total E.U. GDP to $8.5 \%$ for intermediate migration costs and then onto $6.5 \%$ for low migration costs). This happens because immigration increases the concentration of production and demand in the West and decreases demand from the East, resulting in smaller bilateral trade.

The most notable finding, however, is that in terms of real wages, freer migration is beneficial to each country overall and to most groups in each country. The price level (first row in Table 4) decreases in both regions. ${ }^{45}$ The highly educated from Eastern Europe are used more efficiently in the West and help create a wider range of varieties of good $X$. These efficiency gains from the relocation of labor spill over to the East in the form of reduced prices of traded goods. As proved theoretically under free trade, the productivity gain of migrants are large enough to more than offset the increased trade costs incurred by Country 2 to buy the new varieties. Consequently, there is a real wage gain for the workers remaining in Country 2 from the migration of their conationals. Real income increases for the average native worker in each country. Following Clemens and Pritchett (2008) we compare income "per natural", that is, the average income earned by natives of a country, regardless of where they reside. ${ }^{46}$ Looking at income per natural, reported in the third row of Table 4 , we observe that it increases by $0.8 \%$ in Western Europe and by $38 \%$ in Eastern Europe going from specification I to III. By contrast, the comparison of income per capita misses most of this positive effect for two reasons. First, the increased wages of emigrants from Eastern Europe are not recorded in the income of Eastern Europe. Second, the migration of highly educated migrants, while helping rather than hurting the income of those who remain,

\footnotetext{
${ }^{44}$ Although not reported on the Table, $Z_{2}^{T M H}$ equals 0.78 , which corresponds to completed secondary education.

${ }^{45}$ With respect to the current situation, the change in the price level in the West would be equal to $-0.6 \%$ and $-2.1 \%$ for intermediate and low legal costs respectively, while for the East these price reductions would be $-0.09 \%$ and $-1.4 \%$.

${ }^{46}$ Clemens and Pritchett (2008) argue convincingly that "income per natural" rather than "income per person" should be used to evaluate the beneficial effects of migration.
} 
decreases the average education and income of the East, due to a compositional effect. In short, although international migration benefits almost every group, an analysis based on income per capita at the country level would show an income loss in each country because of the compositional effects.

As for the effect on real wages by educational group, they are reported in the central rows of Table 4 and for Eastern nationals, in the case of migration, they are differentiated between those who stay and those who migrate. For Western Europe, the move towards freer labor mobility helps the less educated (a 2.1\% increase in the real wages of workers with less than primary education going from specification I to III) and hurts slightly the most educated who are negatively affected by the increased supply of highly educated migrants (about $-0.9 \%$ change in the average wages of the college educated). As for workers in Eastern Europe, the highly educated who migrate gain the most. ${ }^{47}$ At the same time, all workers who remain in Eastern Europe also obtain real gains of $1.4 \%$ of their current wage relative to the case with no migration. ${ }^{48}$ This gain stems entirely from the lower prices and the larger variety of goods that those workers enjoy via trade.

\section{Conclusion}

This paper develops a model of international migration that combines technological differences across countries, trade of a differentiated good and heterogeneous workers. This fills a gap in the literature. Trade and migration tend to be analyzed separately and, to our knowledge, no model exists that analyzes the patterns of (and gains from) trade and migration in a setup combining technological differences and differences in factor endowments (workers' skills). The model produces interesting qualitative predictions about the patterns of migration, productive specialization and wages when labor mobility (in addition to trade) is allowed. We apply the model to an important case of economic integration: East-West European economic integration. Calibrated to match the main economic features of Eastern and Western Europe, we simulate the comparison (comparative statics) between the case of no economic interactions (the pre-1990 situation) and almost free trade (as of year 2004). We then use the model to predict the (long-run) effects of reducing the legal costs of migration between the two regions.

Our simulations show that if the legal costs of migration between East and West were reduced by half, about $9 \%$ of the Eastern European population of working age would eventually move to the West, and those migrants would be selected among highly educated workers. This would benefit Europe as a whole by increasing

\footnotetext{
${ }^{47}$ Table 4 report the real wages received by the migrants but not the consumption-equivalent wages. In order to translate the real wages received into utility or consumption-equivalents one needs to substract the psychological costs (estimated at $20 \%$ of the wage).

${ }^{48}$ It is important to notice that, due to the migration of some workers within the group, the average real wages by educational group in Eastern Europe reported in specifications I through III in Table 4 are not based on the same workers' skill distribution, and thus cannot be directly compared. When we consider workers of comparable skills, the difference in the real wages of Eastern Europe between specifications I and III across all educational groups amounts to $1.4 \%$, equal to the difference in the price level between both specifications.
} 
the income per natural of Western Europe by $0.3 \%$ and that of Eastern Europe by 9.5\%. Most of these benefits accrue to the highly educated workers who migrate. However, trade spreads the benefits in the form of more and cheaper varieties of goods and services also available to workers in Eastern Europe. The least educated workers in the East, as well as those in the West, would gain from migration (between 0.1 and $0.6 \%$ of their wage). The only group that would somehow suffer from these migration patterns would be the highly educated in the West who would experience a relatively small real wage loss $(-0.18 \%)$. 


\section{A Details of Proofs of Propositions 1 to 4}

We use the implicit function theorem applied to the equilibrium condition (14) to derive the dependence of $\bar{Z}_{j}$ on all parameters. In some cases it is useful to re-write that equilibrium condition as follows:

$$
\left(\frac{\beta}{1-\beta}\right)^{\theta} \int_{0}^{\bar{Z}_{j}} \exp \left(g_{Y j} Z\right) d G_{j}(Z)=C_{X} P_{X}^{\theta-1}\left(\int_{\bar{Z}_{j}}^{1} \exp \left(g_{X j} Z\right) d G_{j}(Z)\right)
$$

Applying Leibniz's rule to differentiate $\Im\left[\bar{Z}_{j}, g_{Y}, g_{X j}, \beta, \sigma, \theta, M_{j}, F_{X j}, G_{j}(Z)\right]$ as defined in (14) with respect to $\bar{Z}_{j}$, if $g_{X j}>g_{Y j}$ and $\sigma>\theta$ it is easy to verify that the derivative $\partial \Im / \partial \bar{Z}_{j}$ is the sum of three positive terms and hence is positive.

Details of the Proof of Proposition 1: It is easy to verify that $\partial \Im / \partial M_{j}>0$. Thus, for the implicit function theorem $\partial \bar{Z}_{j} / \partial M_{j}=-\left(\Im / \partial \bar{Z}_{j} / \partial \Im / \partial M_{j}\right)<0$, so that an increase in $M_{j}$ decreases $\bar{Z}_{j}$. From equation $(20)$ a decrease in $\bar{Z}_{j}$ implies that the left hand side of the equation decreases while $C_{X}$ and the integral on the right hand side increase. This implies that $P_{X}$ must decrease in order to maintain the equality. Therefore, the share of income spent (and produced) in sector $X, s\left(P_{X j}\right)=\left(\beta^{\theta} P_{X j}^{1-\theta}\right) /\left[\beta^{\theta} P_{X j}^{1-\theta}+(1-\beta)^{\theta}\right]$, increases as long as $\theta>1$. The results described in the proposition are easily derived from the increase in $C_{X}$ and $s\left(P_{X}\right)$ and the decrease in $P_{X}$.

Details of the Proof of Proposition 2: It is easy to verify that $\partial \Im / \partial \Lambda_{j}>0$. Thus, for the implicit function theorem $\partial \bar{Z}_{j} / \partial \Lambda_{j}=-\left(\Im / \partial \bar{Z}_{j} / \partial \Im / \partial \Lambda_{j}\right)<0$, so that an increase in $\Lambda_{j}$ decreases $\bar{Z}_{j}$. As in the case of proposition 1, this must imply a decrease in $P_{X}$. In this case not only do real wages in sector $X$ increase due to an increase in $C_{X}$ and a decrease in $P$, but also due to the increase in $\Lambda_{j}$ (see expression (8)). Similarly, real wages in sector $Y$ increase due to a decrease in $P$ and an increase in $\Lambda_{j}$.

Details of the Proof of Proposition 3: For $\theta=1$ it is easy to prove that $\partial \Im / \partial g_{X}<0$ so that $\partial \bar{Z}_{j} \partial g_{X}>0$. Intuitively, an increase in $g_{X}$ has two effects on the second term of expression (14): it decreases the term $\frac{1}{\exp \left(\theta g_{X j} \bar{Z}_{j}\right)}$ while it increases $\left(\int_{\bar{Z}_{j}}^{1} \exp \left(g_{X j} Z\right) d G_{j}(Z)\right)^{\frac{\sigma-\theta}{\sigma-1}}$. The first effect is smaller for $\theta=1$, as it is calculated at $\bar{Z}_{j}$ while the effect on the integral is calculated at all values between $\bar{Z}_{j}$ and 1 . Hence the second effect prevails, and with the negative sign in front this implies $\partial \Im / \partial g_{X}<0$. This is still true as long as $\theta$ is not too large, but for high $\theta$ the effect is reversed. In the new equilibrium with higher $g_{X}$ and higher $\bar{Z}_{j}$, considering each term in (14), the first integral term certainly increases and $C_{X}$ decreases, so the second integral must have increased to preserve the equality. If $\int_{\bar{Z}_{j}}^{1} \exp \left(g_{X j} Z\right) d G_{j}(Z)$ increases in the new equilibrium, then the number of varieties, $N_{X}$, must increase (as per expression 12) and the price index $P_{X}$ must decrease (see expression 11) due to the increase in $N_{X}$ and the decrease in $C_{X}$. The other implications follow easily from these two results. 
Details of the Proof of Proposition 4: Consider a shift in the density $d G_{j}(Z)$ which shifts workers from skills below or at $\bar{Z}_{j}$ to skills above $\bar{Z}_{j}$. This implies a decrease in the term $\int_{0}^{\bar{Z}_{j}} \exp \left(g_{Y j} Z\right) d G_{j}(Z)$ and an increase in the term $\int_{\bar{Z}_{j}}^{1} \exp \left(g_{X j} Z\right) d G_{j}(Z)$. Hence the overall value of $\Im\left[\bar{Z}_{j}, g_{Y}, g_{X j}, \beta, \sigma, \theta, M_{j}, F_{X j}, G_{j}(Z)\right]$ would decrease so that $\partial \Im / \partial G_{j}(Z)<0$ and for the implicit function theorem $\partial \bar{Z}_{j} / \partial G_{j}(Z)=-\left(\Im / \partial \bar{Z}_{j} / \partial \Im / \partial G_{j}(Z)\right)>0$. As for proposition 3, this implies a decrease in $C_{X}$ and a decrease in $P_{X}$ and therefore a decrease in $P$. The other results follow from these.

\section{B Equilibrium Conditions with (Costly) Trade}

The equilibrium number of firms and varieties in country $j$ in the presence of trade is given by an expression identical to (12), while substituting (12) into (16) we obtain the expression for $P_{X}$ :

$P_{X j}=\frac{\sigma}{\sigma-1}\left[\frac{M_{j} \Lambda_{j}}{\sigma F_{X j}} C_{X j}^{1-\sigma} \int_{\bar{Z}_{j}^{T}}^{1} \exp \left(g_{X j} Z\right) d G_{j}(Z)+\frac{M_{i} \Lambda_{i}}{\sigma F_{X i}}\left(\tau C_{X i}\right)^{1-\sigma} \int_{\bar{Z}_{i}^{T}}^{1} \exp \left(g_{X i} Z\right) d G_{i}(Z)\right]^{\frac{1}{1-\sigma}} \quad i, j=1,2 \quad i \neq j$

As explained, the cut-off skill levels $\bar{Z}_{j}^{T}, j=1,2$, are pinned down by the world market clearing conditions for good $Y$, for the varieties of good $X$ produced in Country 1 and those produced in Country 2. Once we incorporate the trade-balance conditions $\left(E_{1}=M_{1} \bar{W}_{1}, E_{2}=M_{2} \bar{W}_{2}\right)$ and the expression for the number of varieties (12) these can be written as follows:

$$
\begin{aligned}
{\left[1-s\left(P_{X 1}\right)\right] M_{1} \bar{W}_{1}+\left[1-s\left(P_{X 2}\right)\right] M_{2} \bar{W}_{2} } & =M_{1} \Lambda_{1} \int_{0}^{\bar{Z}_{1}^{T}} \exp \left(g_{Y 1} Z\right) d G_{1}(Z)+M_{2} \Lambda_{2} \int_{0}^{\bar{Z}_{2}^{T}} \exp \left(g_{Y 2} Z\right) d G_{2}(Z) \\
s\left(P_{X 1}\right) M_{1} \bar{W}_{1}\left(\frac{p_{1}^{1-\sigma}}{P_{X 1}^{1-\sigma}}\right)+s\left(P_{X 2}\right) M_{2} \bar{W}_{2}\left(\frac{\left(p_{1} \cdot \tau\right)^{1-\sigma}}{P_{X 2}^{1-\sigma}}\right) & =(\sigma-1) F_{X 1} p_{1} \\
s\left(P_{X 1}\right) M_{1} \bar{W}_{1}\left(\frac{\left(p_{2} \cdot \tau\right)^{1-\sigma}}{P_{X 1}^{1-\sigma}}\right)+s\left(P_{X 2}\right) M_{2} \bar{W}_{2}\left(\frac{p_{2}^{1-\sigma}}{P_{X 2}^{1-\sigma}}\right) & =(\sigma-1) F_{X 2} p_{2}
\end{aligned}
$$

Proof of the Corollary to Proposition 5: Consider equilibrium equation (17). For given relative fixed costs $\frac{F_{X 1}}{F_{X 2}}$, an increase in the ratio $\frac{\left(g_{X 1}-g_{Y 1}\right)}{\left(g_{X 2}-g_{Y 2}\right)}$ must imply a decrease in the ratio $\bar{Z}_{1}^{T} / \bar{Z}_{2}^{T}$. This in turn implies that in Country 1 more workers move into sector $X$ (lower $\bar{Z}_{1}^{T}$ ) and thus Country 1 becomes relatively more specialized in that sector while Country 2 becomes relatively more specialized in sector $Y\left(\bar{Z}_{2}^{T}\right.$ increases). Notice also that given that $g_{X 2}>g_{Y 2}$ and $\frac{F_{X 1}}{F_{X 2}}>1$ (a restriction assumed in section 3 to reflect that more advanced technologies require higher fixed costs), there can be no equilibrium in which Country 1 completely specializes in sector $X$ 
(i.e., $\left.\bar{Z}_{1}^{T}=0\right)$ under free trade. However, there can be equilibria in which Country 2 fully specializes in sector $Y$ $\left(\bar{Z}_{2}^{T}=1\right)$ which occurs when the inter-sectoral technological differences between countries (the ratio $\left.\frac{\left(g_{X 1}-g_{Y 1}\right)}{\left(g_{X 2}-g_{Y 2}\right)}\right)$ are particularly large.

\section{Equilibrium Conditions with (Costly) Trade and Migration}

Besides the migration skill levels $\bar{Z}_{2}^{T M H}$ and $\bar{Z}_{2}^{T M L}$ (given by conditions similar to 19), the other relevant skill levels are the thresholds determining the assignment of workers between sectors $X$ and $Y$ in Countries 1 and 2, denoted by $\bar{Z}_{1}^{T M}$ and $\bar{Z}_{2}^{T M}$ respectively. The inter-sectoral cut-offs are pinned down by the market-clearing conditions for goods $\mathrm{Y}$, for the varieties of good $X$ produced in Country 1 and those produced in Country 2, whose expressions are now as follows:

$$
\begin{aligned}
& {\left[1-s\left(P_{X 1}\right)\right] M_{1} \bar{W}_{1}+\left[1-s\left(P_{X 2}\right)\right] M_{2} \bar{W}_{2}=} \\
& M_{1} \Lambda_{1} \int_{0}^{\bar{Z}_{1}^{T M}} \exp \left(g_{Y 1} Z\right) d G_{1}(Z)+M_{2}\left(\Lambda_{1}\left[1-\delta_{H}\right] \int_{0}^{\bar{Z}_{2}^{T M L}} \exp \left(g_{Y 1} Z\right) d G_{2}(Z)-\int_{0}^{\bar{Z}_{2}^{T M L}} D_{B} d G_{2}(Z)\right)+ \\
& +M_{2} \Lambda_{2} \int_{\bar{Z}_{2}^{T M L}}^{\bar{Z}_{2}^{T M}} \exp \left(g_{Y 2} Z\right) d G_{2}(Z) \\
& s\left(P_{X 1}\right) M_{1} \bar{W}_{1}\left(\frac{p_{1}^{1-\sigma}}{P_{X 1}^{1-\sigma}}\right)+s\left(P_{X 2}\right) M_{2} \bar{W}_{2}\left(\frac{\left(p_{1} \cdot \tau\right)^{1-\sigma}}{P_{X 2}^{1-\sigma}}\right)=(\sigma-1) F_{X 1} p_{1} \\
& s\left(P_{X 1}\right) M_{1} \bar{W}_{1}\left(\frac{\left(p_{2} \cdot \tau\right)^{1-\sigma}}{P_{X 1}^{1-\sigma}}\right)+s\left(P_{X 2}\right) M_{2} \bar{W}_{2}\left(\frac{p_{2}^{1-\sigma}}{P_{X 2}^{1-\sigma}}\right)=(\sigma-1) F_{X 2} p_{2}
\end{aligned}
$$

Total wages in Countries 1 and 2 are given, respectively, by:

$$
\begin{aligned}
& W_{1}=M_{1} \Lambda_{1} \int_{0}^{\bar{Z}_{1}^{T M}} \exp \left(g_{Y 1} Z\right) d G_{1}(Z)+M_{2}\left(\Lambda_{1}\left[1-\delta_{H}\right] \int_{0}^{\bar{Z}_{2}^{T M L}} \exp \left(g_{Y 1} Z\right) d G_{2}(Z)-\int_{0}^{\bar{Z}_{2}^{T M L}} D_{B} d G_{2}(Z)\right)+ \\
& +M_{1} \Lambda_{1} C_{X 1} \int_{\bar{Z}_{1}^{T M}}^{1} \exp \left(g_{X 1} Z\right) d G_{1}(Z)+M_{2}\left(\Lambda_{1} C_{X 1}\left[1-\delta_{H}\right] \int_{\bar{Z}_{2}^{T M H}}^{1} \exp \left(g_{X 1} Z\right) d G_{2}(Z)-\int_{\bar{Z}_{2}^{T M H}}^{1} D_{B} d G_{2}(Z)\right) \\
& W_{2}=M_{2} \Lambda_{2}\left(\int_{\bar{Z}_{2}^{T M L}}^{\bar{Z}_{2}^{T M}} \exp \left(g_{Y 2} Z\right) d G_{2}(Z)+C_{X 2} \int_{\bar{Z}_{2}^{T M}}^{\bar{Z}_{2}^{T M H}} \exp \left(g_{X 2} Z\right) d G_{2}(Z)\right)
\end{aligned}
$$


Notice that the main difference with respect to the scenario with trade and no migration is that now the output in sectors $Y$ and $X$ in Country 1 might be produced by migrants from Country 2, and migration costs dissipate part of the potential output of those workers.

Once we know the four relevant skill levels, $\bar{Z}_{1}^{T M}, \bar{Z}_{2}^{T M}, \bar{Z}_{2}^{T M L}$ and $\bar{Z}_{2}^{T M H}$, we can compute the number of varieties and the price of the composite good $X$ in each country as follows:

$$
\begin{gathered}
N_{1}=\frac{1}{\sigma F_{X 1}}\left[M_{1} \Lambda_{1} \int_{\bar{Z}_{1}^{T M}}^{1} \exp \left(g_{X 1} Z\right) d G_{1}(Z)+M_{2}\left(\Lambda_{1}\left[1-\delta_{H}\right] \int_{\bar{Z}_{2}^{T M H}}^{1} \exp \left(g_{X 1} Z\right) d G_{2}(Z)-\int_{\bar{Z}_{2}^{T M H}}^{1} D_{B} d G_{2}(Z)\right)\right] \\
N_{2}=\frac{M_{2} \Lambda_{2}}{\sigma F_{X 2}} \int_{\bar{Z}_{2}^{T M}}^{\bar{Z}_{2 M H}^{T M}} \exp \left(g_{X 2} Z\right) d G_{2}(Z) \\
P_{X j}=\frac{\sigma}{\sigma-1}\left[C_{X j}^{1-\sigma} N_{j}+\left(\tau C_{X i}\right)^{1-\sigma} N_{i}\right]^{\frac{1}{1-\sigma}} \quad i, j=1,2 \quad i \neq j
\end{gathered}
$$

Two final remarks are in order. If migration costs are too high, the lower migration threshold $\bar{Z}_{2}^{T M L}$ will be 0 and condition (19) will be satisfied for a relatively high value of $\bar{Z}_{2}^{T M H}$. On the other hand, if migration costs are very low (but not so low as to have all workers migrate) Country 2 would lose most of its highly skilled workers with the possible consequence of also losing its advanced sector X. In this case the above equilibrium conditions would still be valid if one replaces $\bar{Z}_{2}^{T M}$ (the inter-sectoral skill threshold) with $\bar{Z}_{2}^{T M H}$ (the migration threshold for high-skilled workers). 


\section{References}

Beine, M., F. Docquier and H. Rapoport, 2001. "Brain Drain and Economic Growth: Theory and Evidence", Journal of Development Economics 64:1, 275-289.

Bhagwati, J. and K. Hamada, 1974. "The Brain Drain, International Integration of Markets for Professionals and Unemployment: A Theoretical Analysis", Journal of Development Economics 1:1, 19-42.

Bhagwati, J. and C. Rodriguez, 1975. "Welfare-Theoretical Analysis of the Brain Drain", Journal of Development Economics 2:3, 195-222.

Barro, R. and Lee, J., 2001. "International Data on Educational Attainment: Updates and Implications", Oxford Economic Papers 53:3, 541-563.

Benhabib, J. and B. Jovanovic, 2007. "Optimal Migration: a World Perspective", NBER Working Paper \# 12871, Cambridge MA.

Boeri, T. and H. Brucker, 2005. "Why Are Europeans So Tough on Migrants?", Economic Policy, 20:44, 629-703.

Borjas, G., 1996. "The Earnings of American Immigrants in the United States", Journal of Development Economics 51:1, 69-98.

Broda, C. and D. Weinstein, 2006. "Globalization and the Gains from Variety", Quarterly Journal of Economics 121:2, 541-585.

Broda, C. and D. Weinstein, 2004. "Variety Growth and World Welfare", American Economic Review Papers and Proceedings 94:2, 139-144.

Caselli, F. and W. J. Coleman, 2006. "The World Technology Frontier", American Economic Review 96:3, 499-522.

Ciccone, A. and G. Peri, 2005. "Long-Run Substitutability between More and Less Educated Workers: Evidence from U.S. States 1950-1990", Review of Economics and Statistic 87:4, 652-663.

Clemens M. and L. Pritchett, 2008. "Income per Natural: Measuring Development for People rather than Places", Population and Development Review, 34:3, 395-434.

Davis, D. and D. Weinstein, 2002. "Technological Superiority and the Losses from Migration", NBER Working Paper No. 8971, Cambridge, MA.

Docquier, F. and A. Marfouk, 2005. "International Migration by Educational Attainment (1990-2000). Release 1.1”, Manuscript, Faculté des Sciences Sociales, Politiques et Économiques, Université Libre de Bruxelles. 
Feenstra, R., 2008. Advanced International Trade: Theory and Evidence, Princeton University Press.

Freeman, R., 2006. "People Flows in Globalization", Journal of Economic Perspectives, 20: 2, 145-70.

Friedberg, R., 2000. "You Can't Take it With You? Immigrant Assimilation and the Portability of Human Capital," Journal of Labor Economics 18:2, 221-251.

Grogger J. and G. Hanson, 2008. "Income Maximization and the Selection and Sorting of International Migration", NBER Working Paper No. 13821, Cambridge, MA.

Hall, R. and C. I. Jones, 1999. "Why do Some Countries Produce So Much More Output Per Worker than Others?", Quarterly Journal of Economics 114:1, 83-116.

Hatton, T.J. and J. Williamson, 2005. "A Dual Policy Paradox: Why Have Trade and Immigration Policies Always Differed in Labor-Scarce Economies?", NBER Working Paper 11866, Cambridge MA.

Hatton, T.J. and J. Williamson, 2006. "What Determines Immigration's Impact: Comparing Two Global Centuries", NBER Working Paper \# 12414, Cambridge MA.

Hummels, D., 2007. "Transport Costs and International Trade in the Second Era of Globalization", Journal of Economic Perspectives 21:3, 131-154.

Iranzo, S. and G. Peri, 2009. "Schooling Externalities, Technology and Productivity: Theory and Evidence from U.S. States", The Review of Economics and Statistics, Vol. 91:2.

Iranzo, S. and G. Peri, 2007. "Migration and Trade in a World of Technological Differences: Theory with an Application to Eastern-Western European Integration” NBER Working Paper \#13631.

Kapur, D. and J. McHale, 2005. Give Us Your Best and Brightest: The Global Hunt for Talent and its Impact on the Developing World, Center for Global Development, Brookings Institution Press, Washington DC.

Katz, L. and K. Murphy, 1992. "Changes in Relative Wages 1963-1987- Supply and Demand Factors", Quarterly Journal of Economics 107:1, 35-78.

Klein, P. and G. J. Ventura, 2007. "TFP Differences and the Aggregate Effects of Labor Mobility in the Long Run", The B.E. Journal of Macroeconomics 7:1 (Contributions), Article 10.

Klein, P. and G. J. Ventura, 2006. "Productivity Differences and the Dynamic Effects of Labor Movements", Manuscript University of Western Ontario, August 2006.

Kremer, M. and S. Watt, 2006. "The Globalization of Household Production", Manuscript Harvard University, December 2006 
Krugman P. (1981) "Intraindustry Specialization and the Gains from Trade" Journal of Political Economy 89:5, 959-973.

Krugman, P. and M. Obtsfeld, 2006. International Economics: Theory and Policy, Seventh Edition, AddisonWesley.

Kuhn, P. and C. McAusland, 2006. "The International Migration of Knowledge Workers: When is Brain Drain Beneficial?", NBER Working Paper \# 12761, Cambridge MA.

Lucas R.E., 1990. "Why Doesn't Capital Flow from Rich to Poor Countries?" American Economic Review, 80:2, 92-96.

Miyagiwa K., 1991. "Scale Economies in Education and the Brain Drain Problem" International Economic Review, 32:3, 743-759.

Mountford A., 1997. "Can a Brain Drain be Good in the Source Economy?" Journal of Development Economics $53: 2,287-303$.

Mundell, R.A., 1957. "International Trade and Factor Mobility", American Economic Review 47:3, 321-335.

Psacharopoulos, G. and H. Patrinos, 2004. "Returns to Investment in Education: A Further Update", Education Economics 12:2, $111-134$.

Rauch J., 1991. "Reconciling the Pattern of Trade with the Pattern of Migration" American Economic Review, 81:4, 759-796.

Rauch J., 1999. "Networks versus Markets in International Trade", Journal of International Economics 48:1, $7-35$.

Rauch, J. and V. Trinidade, 2002. "Ethnic Chinese Networks in International Trade", Review of Economics and Statistics 84:1, 116-130.

Stark, O., 2004. "Rethinking the Brain Drain", World Development 32:1, 15-22.

Wong, K.Y.1986. "Are international trade and factor Mobility Substitutes?", Journal of International Economics $21: 1 / 2,25-44$.

Wong, K.Y.and C. K.Yip, 1999. "Education, Economic Growth and Brain Drain", Journal of Economic Dynamics and Control 23, 699-726.

Yeaple, S., 2005. "A Simple Model of Firm Heterogeneity, International Trade and Wages", Journal of International Economics 65, 1-20. 

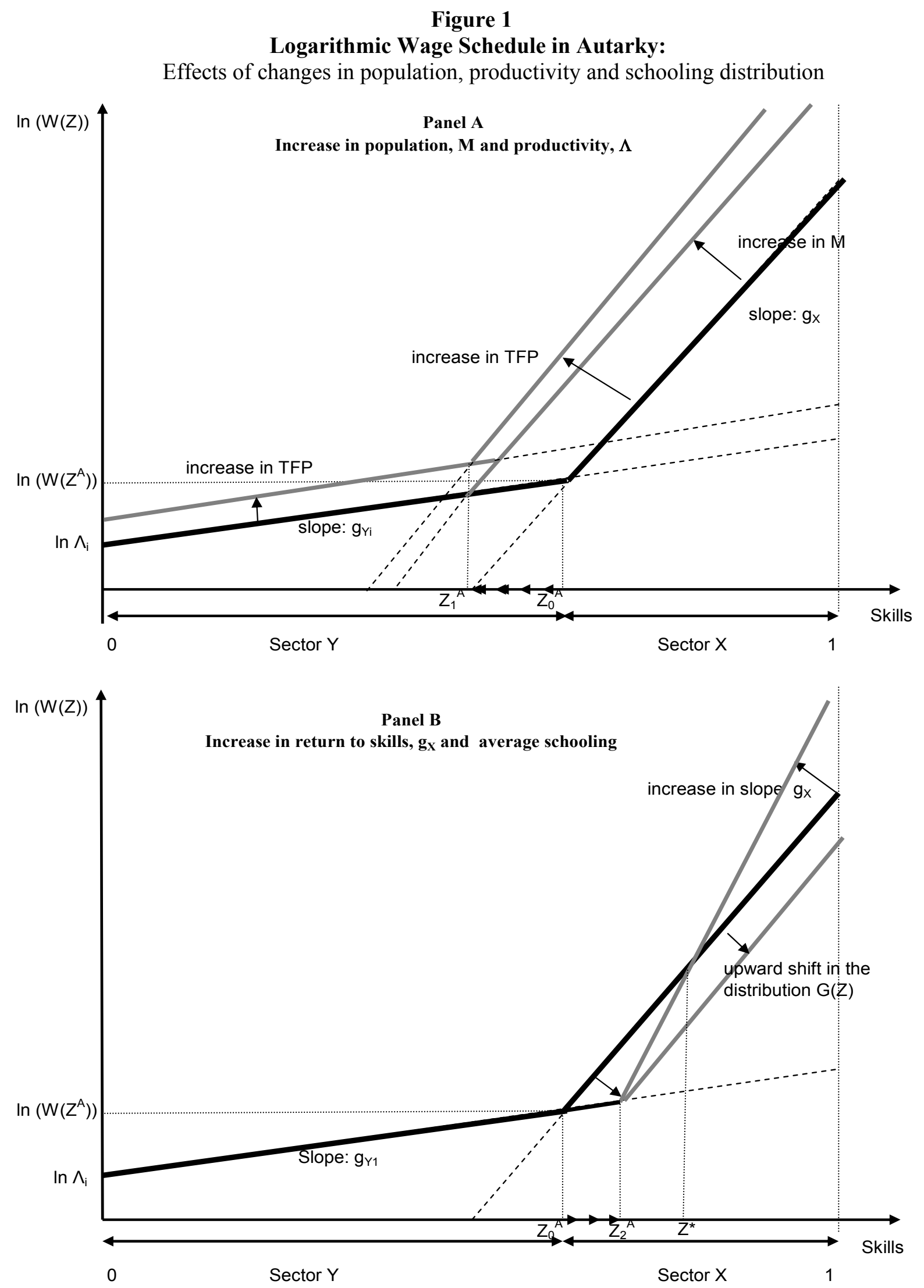

Notes: The horizontal axis measures the skill (schooling) level of workers, standardized to be between 0 and 1 . The vertical axis measures the natural logarithm of the wage in terms of the numeraire good Y. 
Figure 2

Logarithmic Real Wage Schedules in Autarky:

Western Europe (Country 1) and Eastern Europe (Country 2)
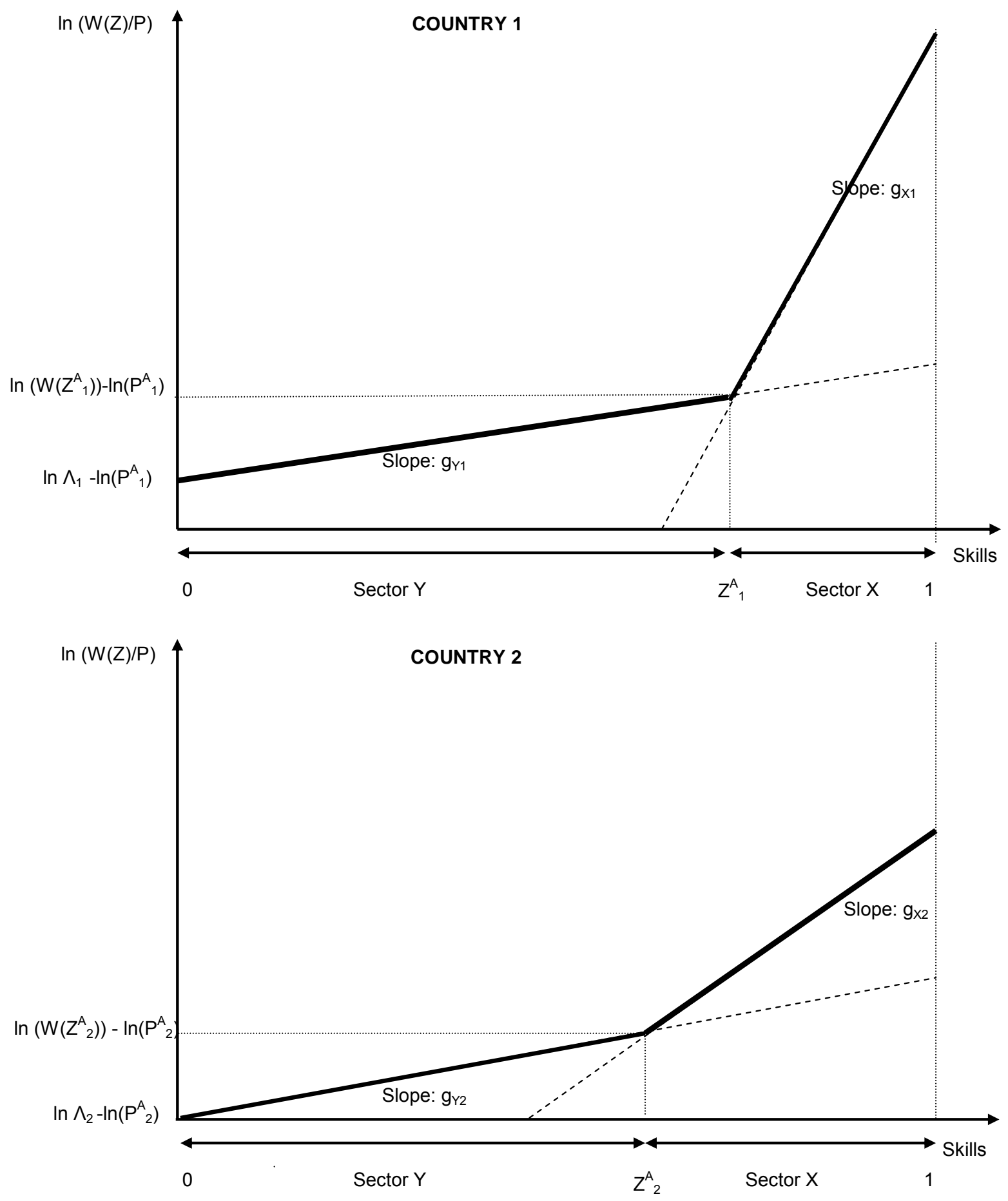

Notes: The horizontal axis measures the skill (schooling) level of workers, standardized to be between 0 and 1 . The vertical axis measures the natural logarithm of the wage in real (representative basket) units. 
Figure 3

Incentives to Migrate:

Comparison between logarithmic real wages in Country 2 and logarithmic real wages, net of migration costs, in Country 1

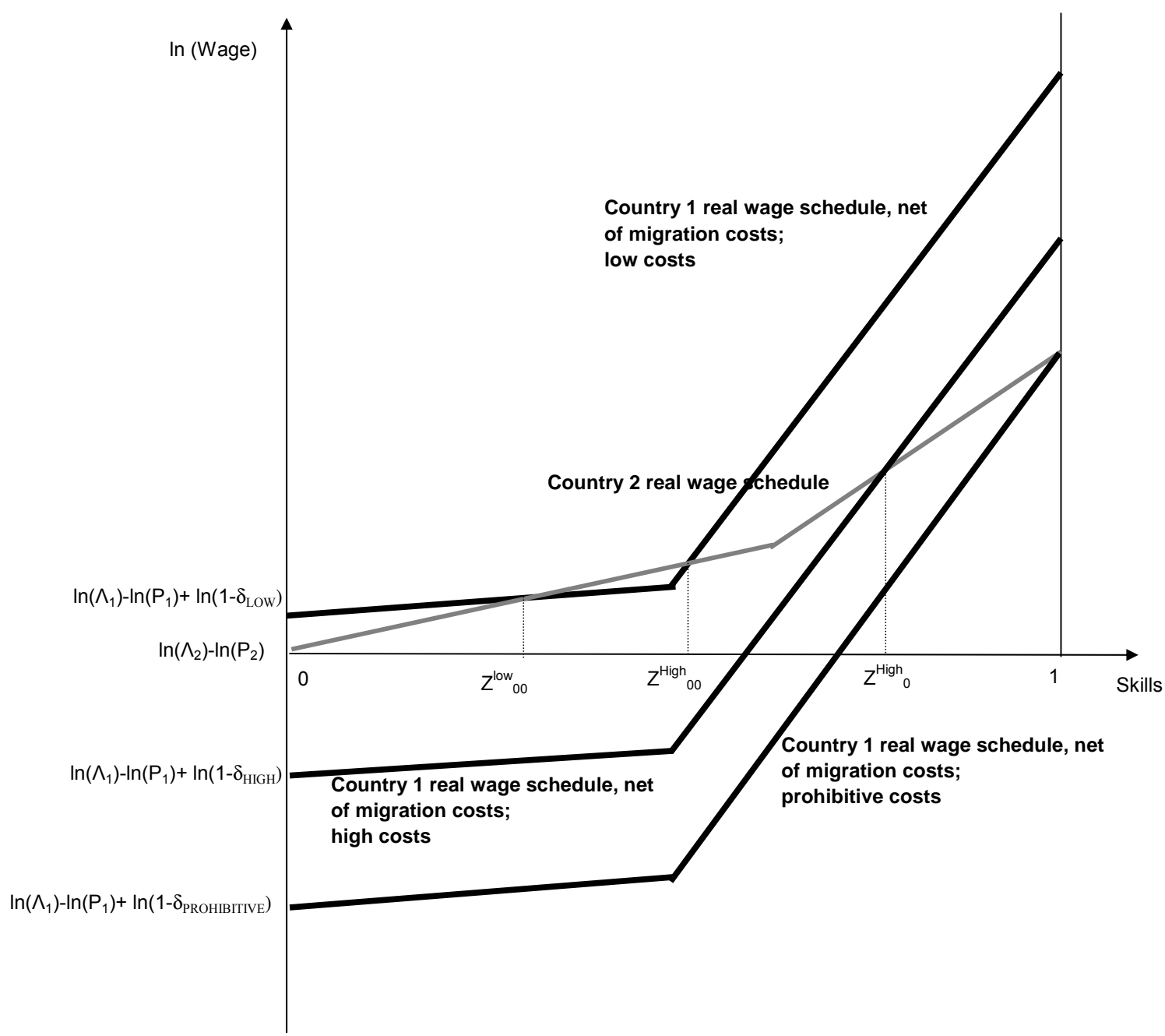

Notes: The migration costs $\delta$ are assumed to be proportional to wages. The vertical distance between the two lines measures the gains from migrating from Country 2 to Country 1 for workers of skill level $\mathrm{Z}$. This gain is positive if the thicker black line lies above the grey line, and is negative (a loss) if the grey line lies above the black one. The lowest black schedule is drawn for prohibitive migration costs, the intermediate one for high migration costs and the highest one for low migration costs. 
Figure 4

From Autarky to Free Trade:

Changes in the logarithmic real wage schedules when the two countries allow free trade
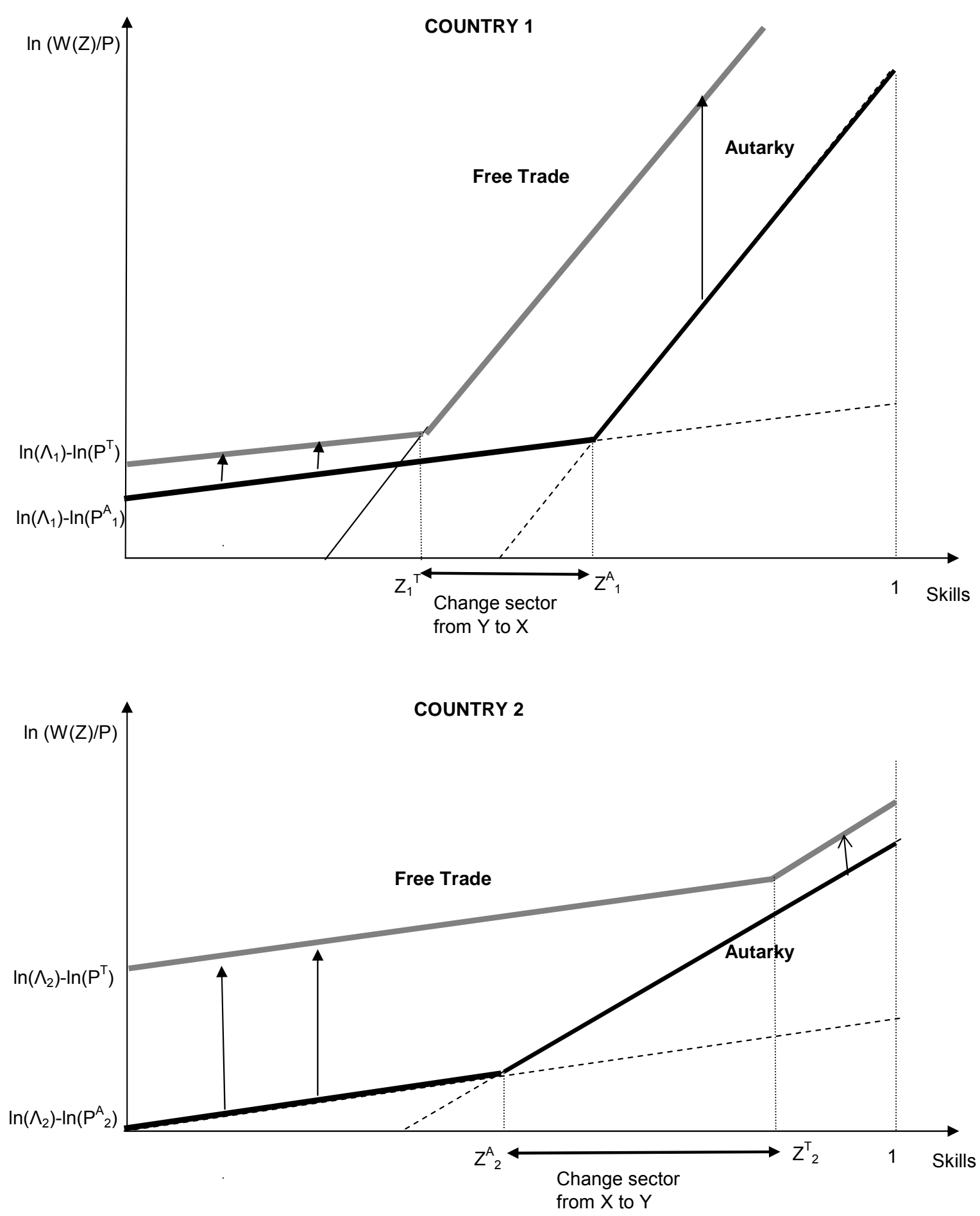

Notes: The horizontal axis measures the skill (schooling) level of workers, standardized to be between 0 and 1. The vertical axis measures the natural logarithm of the real wage. The segment denoted as "Change sector" represents the range of skills of workers who switch sectors when going from autarky to free trade. 
Figure 5

Trade Costs and Relative Specialization:

Share of workers in sector $\mathrm{X}$ in Countries 1 and 2 as a function of trade costs

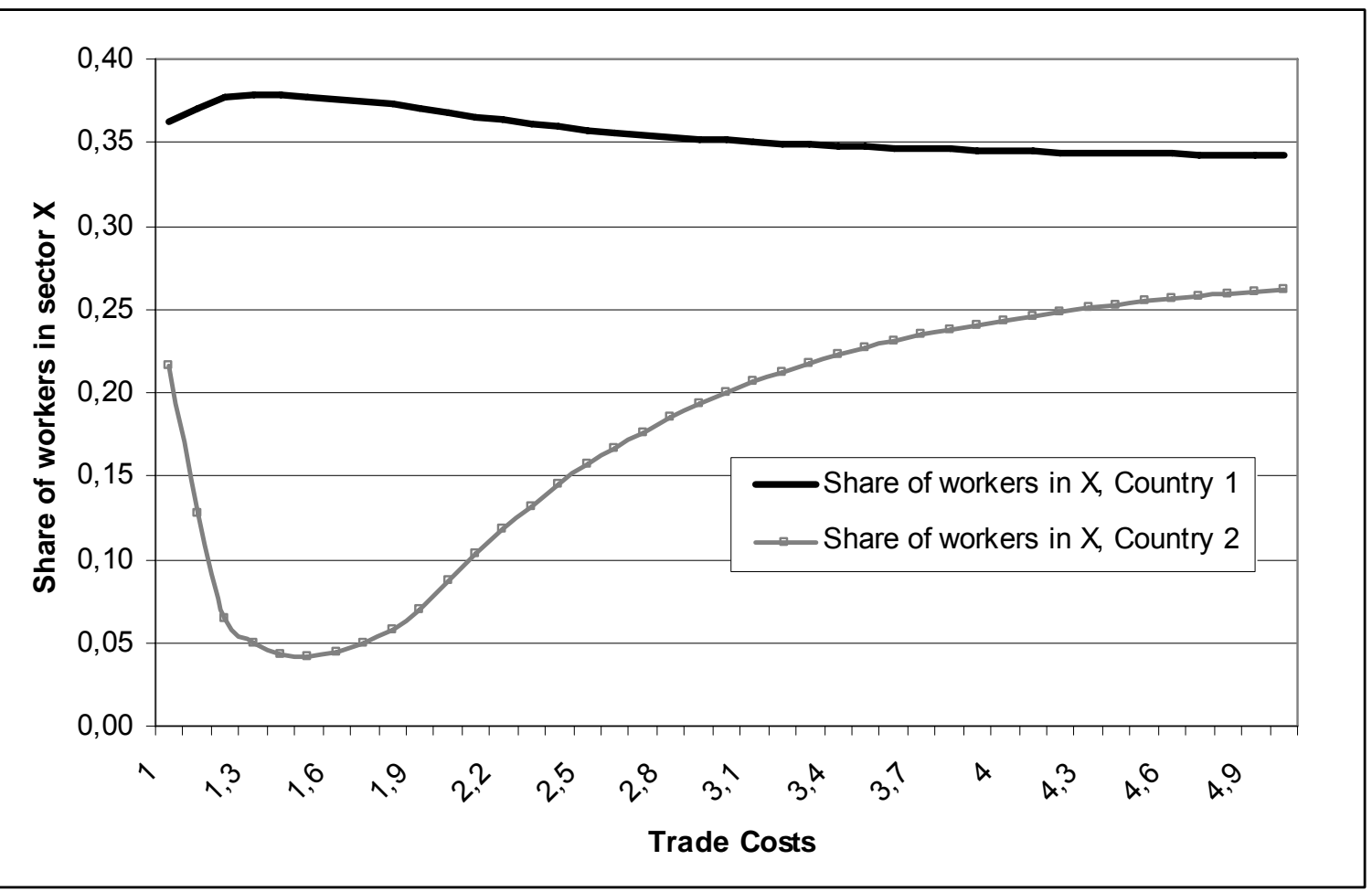

Notes: The simulation represents the share of employment of Country 1 in sector X (in black) and the share of employment of Country 2 in sector X (in grey) for increasing trade costs, $\tau$. The parameter values used in the simulations reproduce the comparative advantage and the employment size of the baseline case in the EastWest European simulation, namely those reported in Table 2. 


\section{Figure 6}

From Free Trade to Trade and Migration:

Changes in the logarithmic real wage schedules when free trade and labor mobility are allowed

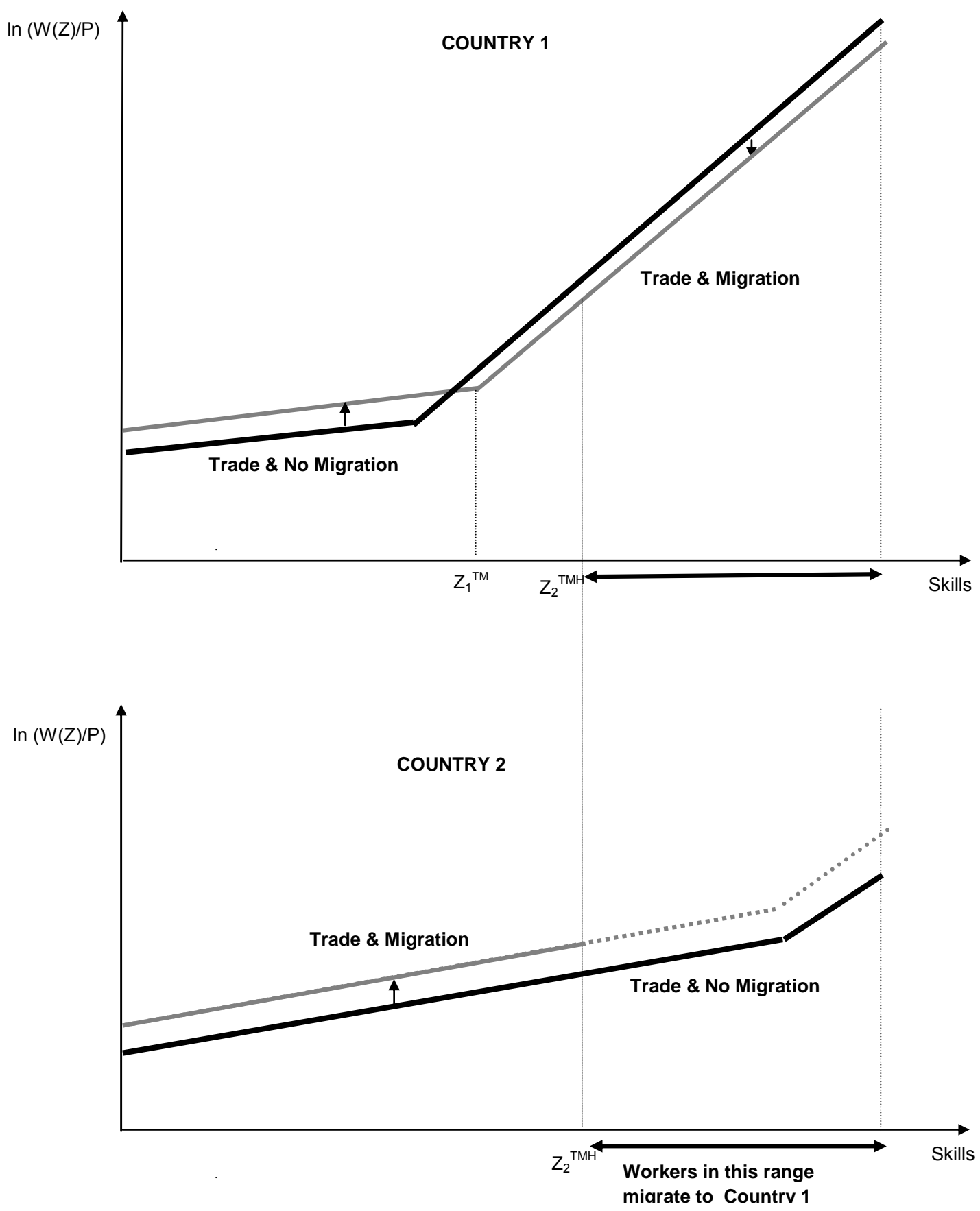

Notes: The horizontal axis measures the skill (schooling) level of workers, standardized to be between 0 and 1 . The vertical axis measures the natural logarithm of the real wage. 
TABLE 1:

EMIGRATION RATES FOR REPRESENTATIVE SOURCE COUNTRIES

\begin{tabular}{|c|c|c|c|c|c|c|c|c|}
\hline & \multicolumn{4}{|c|}{ Emigration Rates in 2000} & \multicolumn{4}{|c|}{ Changes in Emigration Rates 1990-2000 } \\
\hline & $\begin{array}{c}\text { Low } \\
\text { Education }\end{array}$ & $\begin{array}{c}\text { Intermediate } \\
\text { Education }\end{array}$ & $\begin{array}{c}\text { High } \\
\text { Education }\end{array}$ & Total & $\begin{array}{c}\text { Low } \\
\text { Education }\end{array}$ & $\begin{array}{l}\text { Intermediate } \\
\text { Education }\end{array}$ & $\begin{array}{c}\text { High } \\
\text { Education }\end{array}$ & Total \\
\hline China & $0.1 \%$ & $0.1 \%$ & $3.8 \%$ & $0.2 \%$ & $0.0 \%$ & $0.0 \%$ & $0.8 \%$ & $0.1 \%$ \\
\hline India & $0.1 \%$ & $0.4 \%$ & $4.3 \%$ & $0.4 \%$ & $0.0 \%$ & $0.1 \%$ & $1.5 \%$ & $0.1 \%$ \\
\hline Philippines & $1.4 \%$ & $3.3 \%$ & $13.7 \%$ & $5.0 \%$ & $0.1 \%$ & $0.3 \%$ & $0.8 \%$ & $0.8 \%$ \\
\hline Romania & $4.6 \%$ & $2.0 \%$ & $11.8 \%$ & $3.7 \%$ & $1.1 \%$ & $1.1 \%$ & $2.7 \%$ & $1.3 \%$ \\
\hline Eastern Europe & $5.0 \%$ & $3.3 \%$ & $14 \%$ & $5.2 \%$ & $0.5 \%$ & $1.2 \%$ & $0.8 \%$ & $1.1 \%$ \\
\hline
\end{tabular}

Notes: Emigration rates are calculated as the total number of people residing out of the country of origin relative to the working age population in the country of origin by level of education and in the aggregate. Low levels of education include people with 0 to 8 years of schooling, Intermediate levels of education include people with 9 to 12 years of schooling. High levels of education include people with 13 years of schooling or more. "Eastern Europe" only includes the Eastern European countries admitted to the EU in 2004 and 2006.

Source: Docquier and Marfouk (2005). 


\section{Description of the Parameters:}

\section{Population and Education}

$\mathrm{M}_{\mathrm{j}}$ : Total population (Western EU's, standardized to 1)

Share of population with less than primary education

Share of population with primary education

Share of population with secondary education

Share of population with a college degree or more

Technology

$\Lambda_{\mathrm{j}}$ : TFP level (Country 2's is standardized to 1) $\mathrm{g}_{\mathrm{Xj}}$ : Returns to skills (schooling) in sector $\mathrm{X}$

$\mathrm{g}_{\mathrm{Yj}}$ : Returns to skills (schooling) in sector $\mathrm{Y}$

$F_{x j}$ : Fixed cost of development of a variety in $\mathrm{X}$

\section{Western EU Eastern EU}

$\begin{array}{cc}1 & 0.3 \\ 0.13 & 0.06 \\ 0.47 & 0.66 \\ 0.32 & 0.22 \\ 0.08 & 0.06 \\ & \\ 2 & 1 \\ 2 & 1 \\ 0.4 & 0.5 \\ 50 & 3.5\end{array}$

\section{Preferences}

$\theta$ : elasticity of substitution between goods X and Y $\quad 1.5$

$\beta$ : preference for good $\mathrm{X}$ in the utility function $\quad 0.5$

$\sigma$ : elasticity of substitution between varieties of X 4

Notes: The choice of parameters is described in detail in the main text. Parameters related to population and education are obtained from the data, parameters related to technology are either from the literature or calibrated to match the features of Eastern and Western Europe, and the taste parameters, common to the two economies, are taken from the literature. 
TABLE 3: TRADE LIBERALIZATION AND BARRIERS TO MIGRATION

\begin{tabular}{|c|c|c|c|c|c|c|}
\hline & \multicolumn{2}{|c|}{$\begin{array}{l}\text { Autarky } \\
\text { (I) }\end{array}$} & \multicolumn{2}{|c|}{$\begin{array}{l}\text { Free Trade and No } \\
\text { Migration } \\
\text { (II) }\end{array}$} & \multicolumn{2}{|c|}{$\begin{array}{c}\text { Costly Trade }(\tau=1.4) \\
\text { and No Migration } \\
\text { (III) }\end{array}$} \\
\hline & $\begin{array}{l}\text { Western } \\
\text { EU }\end{array}$ & $\begin{array}{l}\text { Eastern } \\
\text { EU }\end{array}$ & $\begin{array}{l}\text { Western } \\
\text { EU }\end{array}$ & $\begin{array}{l}\text { Eastern } \\
\text { EU }\end{array}$ & $\begin{array}{l}\text { Western } \\
\text { EU }\end{array}$ & $\begin{array}{l}\text { Eastern } \\
\text { EU }\end{array}$ \\
\hline Overall price & 1 & 1.341 & 0.992 & 0.992 & 1.004 & 1.139 \\
\hline Real income per capita & 1 & 0.369 & 1.019 & 0.496 & 1.014 & 0.426 \\
\hline \multicolumn{7}{|c|}{ Real wages of workers with educational level: } \\
\hline $\begin{array}{l}\text { - Less than primary (natives) } \\
\text { - Primary (natives) } \\
\text { - Secondary (natives) } \\
\text { - College degree or more } \\
\text { (natives) }\end{array}$ & $\begin{array}{l}0.795 \\
0.895 \\
1.086 \\
1.613\end{array}$ & $\begin{array}{l}0.302 \\
0.351 \\
0.408 \\
0.499\end{array}$ & $\begin{array}{l}0.801 \\
0.903 \\
1.118 \\
1.665\end{array}$ & $\begin{array}{l}0.409 \\
0.475 \\
0.538 \\
0.655\end{array}$ & $\begin{array}{l}0.792 \\
0.892 \\
1.121 \\
1.672\end{array}$ & $\begin{array}{l}0.356 \\
0.413 \\
0.457 \\
0.517\end{array}$ \\
\hline $\begin{array}{l}\text { Employment share in sector Y } \\
\text { Employment share in sector X }\end{array}$ & $\begin{array}{l}66 \% \\
34 \%\end{array}$ & $\begin{array}{l}72 \% \\
28 \%\end{array}$ & $\begin{array}{l}64 \% \\
36 \%\end{array}$ & $\begin{array}{l}81 \% \\
19 \%\end{array}$ & $\begin{array}{l}62 \% \\
38 \%\end{array}$ & $\begin{array}{c}96 \% \\
4 \%\end{array}$ \\
\hline $\begin{array}{l}\text { Total Trade / Total GDP } \\
\% \text { Trade in differentiated } \\
\text { goods }\end{array}$ & \multicolumn{2}{|c|}{$\begin{array}{l}0 \\
0\end{array}$} & \multicolumn{2}{|c|}{$\begin{array}{l}9.9 \% \\
78.4 \%\end{array}$} & \multicolumn{2}{|c|}{$\begin{array}{l}8.9 \% \\
53.9 \%\end{array}$} \\
\hline
\end{tabular}

Notes: The income and wages of both countries in all scenarios have been standardized to the per capita income of country 1 in autarky. Similarly, the prices have been standardized to country 1's price under autarky. Specification (I) shows the Autarky equilibrium with no trade and no labor mobility between countries. Specification (II) shows the case of free trade and no migration. Specification (III) shows the case with no migration and trade costs calibrated to match the volume of trade between Eastern and Western Europe observed in 2004. 
TABLE 4: DECREASING BARRIERS TO MIGRATION WITH COSTLY TRADE, $\tau=1.4$

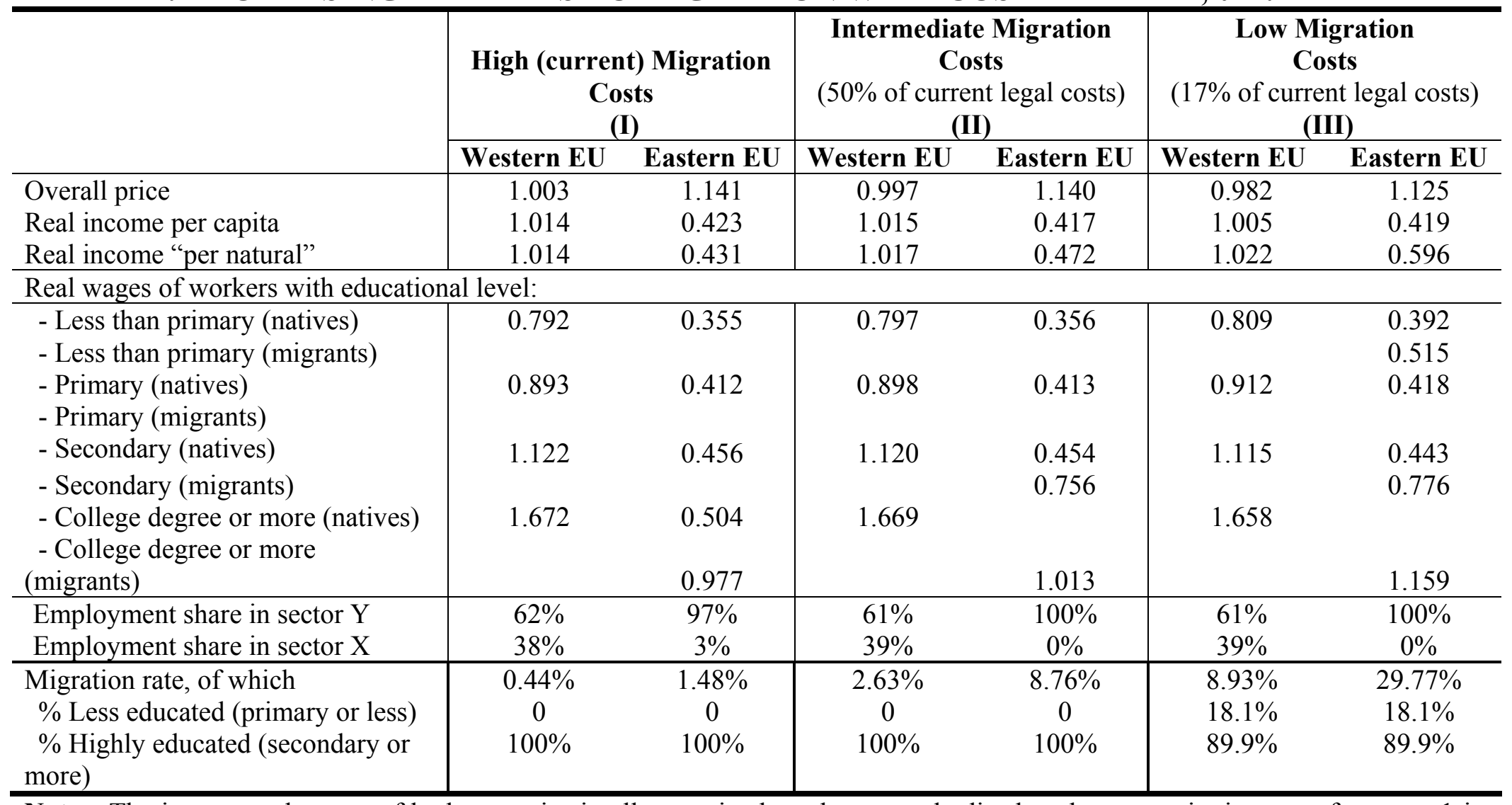

Notes: The income and wages of both countries in all scenarios have been standardized to the per capita income of country 1 in autarky. Similarly, the prices have been standardized to country 1's price under autarky. The wages of migrants reported in the table are net of migration costs due to human capital losses and legal barriers to migrations but do not reflect the psychological costs of migrating. In order to translate these wages into consumption-equivalent terms one needs to substract the psychological costs estimated at $20 \%$.

The legal migration costs used in specification (I) are those costs that yield the observed current migration rate from Eastern Europe with trade costs $\tau=1.4$. They are equal to $26 \%$ of the wage received by the average migrant in Western European Worker. In specification (II) those legal costs are cut to $13 \%$ of migrant-wages in Western Europe and in specification (III) they are reduced to $4 \%$ of those wages. 